\title{
A Comprehensive Motivation of Multilayer Control Levels for Microgrids: Synchronization, Voltage and Frequency Restoration Perspective
}

\author{
Ronald Jackson ${ }^{1}$, Shamsul Aizam Zulkifli ${ }^{1, *(\mathbb{C}, \text {, Mohamed Benbouzid }}{ }^{2, *}$ (), Suriana Salimin ${ }^{1}$, \\ Mubashir Hayat Khan ${ }^{1}$, Garba Elhassan ${ }^{1}$ and Erum Pathan ${ }^{3}$ \\ 1 Department of Electrical Engineering, FKEE, Universiti Tun Hussein Onn Malaysia, Johor 86400, Malaysia; \\ he180095@siswa.uthm.edu.my (R.J.); suriana@uthm.edu.my (S.S.); ge180116@siswa.uthm.edu.my (M.H.K.); \\ ge180033@siswa.uthm.edu.my (G.E.) \\ 2 Institut de recherché Dupuy de Lôme (UMR CNRS 6027 IRDL), University of Brest, 29238 Brest, France \\ 3 Department of Electronic Engineering, Quaid-E-Awam University of Engineering, Science \& \\ Technology Nawabshah, Sindh 67450, Pakistan; ge130108@siswa.uthm.edu.my \\ * Correspondence: aizam@uthm.edu.my (S.A.Z.); Mohamed.Benbouzid@univ-brest.fr (M.B.)
}

Received: 23 October 2020; Accepted: 23 November 2020; Published: 24 November 2020

\begin{abstract}
The current paradigm in integrating intermittent renewable energy sources into microgrids presents various technical challenges in terms of reliable operation and control. This paper performs a comprehensive justification of microgrid trends in dominant control strategies. It covers multilayer hierarchical control schemes, which are able to integrate seamlessly with coordinated control strategies. A general overview of the hierarchical control family that includes primary, secondary, tertiary controls is presented. For power sharing accuracy and capability, droop and non-droop-based controllers are comprehensively studied to address further development. The voltage and frequency restoration techniques are discussed thoroughly based on centralized and decentralized method in order to highlights the differences for better comprehend. The comprehensive studies of grid synchronization strategies also overviewed and analyzed under balanced and unbalanced grid conditions. The details studies for each control level are displayed to highlight the benefits and shortcomings of each control method. A future prediction from the authors' point of view is also provided to acknowledge which control is adequate to be adopted in proportion to their products applications and a possibility technique for self-synchronization is given in this paper.
\end{abstract}

Keywords: microgrid; hierarchical control; primary; secondary control; droop control; frequency restoration; voltage restoration; grid synchronization

\section{Introduction}

The current paradigm in the renewable green energy sector is on the penetration of renewable energy sources (RES) into the electrical system. RES promises an alternative approach for electricity suppliers to produce more sustainable energy as well as to reduce global warming as reported in decarbonization policies [1]. Due to their abundance, RES can penetrate the existing electrical power system and gradually counter the dependency on conventional fossil fuel generation. Worth mentioning, it is a new challenge to meet the energy demand because the power production is not consistent and the demand increases year by year. Henceforth, power electronic converters have mainly dominated in the implementation to increase the efficiency of RES and the reliability of power production with stable generation. For this reason, an embedded electricity generation at a smaller scale is formed and known as distributed generation (DG) units. With the inconsistency of RES power production, the microgrid (MG) has been proposed to manage power distribution and quality aspects [2]. The fundamental 
components in microgrids are depicted in Figure 1, including the scenario during islanded and grid-connected modes.

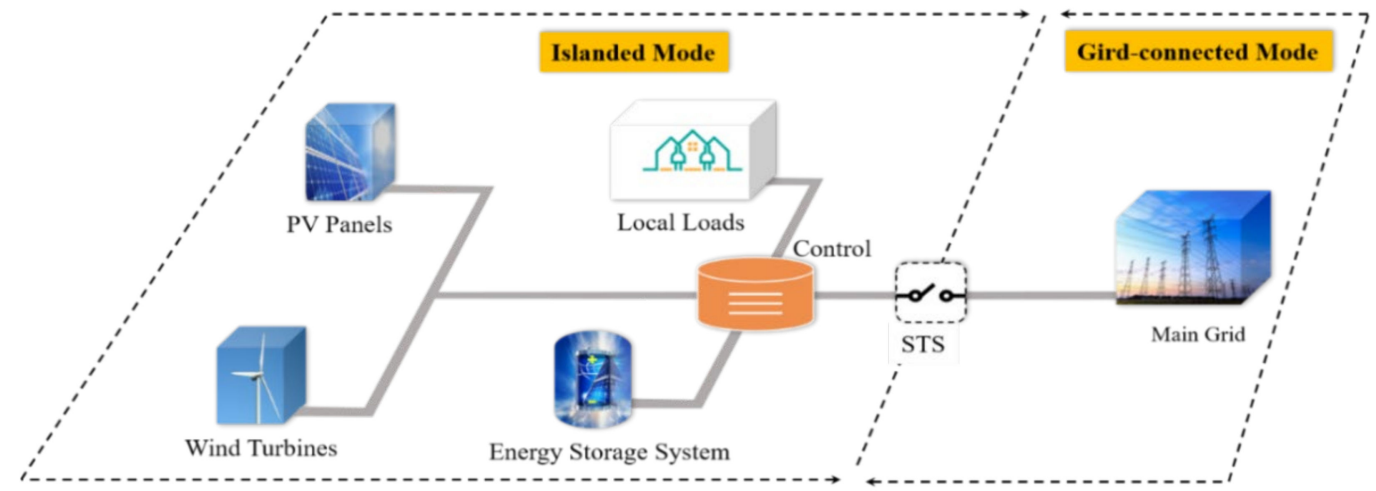

Figure 1. Fundamental microgrid configuration with variable operation modes.

The microgrid can be defined as a cluster of DG units, loads and energy storage system (ESS) operating in coordination to sustainably supply electricity and connecting to the distribution level at a single point of connection, the point of common coupling (PCC). It is designed in such a way so that the power can flow either to the loads and the ESS or to the main grid when the power supply exceeded the microgrid's capacity. A microgrid is capable of operating in two modes: connected to the existing grid network or disconnected from the grid, generally referred to as grid-connected mode (grid-following) and islanded mode (grid-forming), respectively [3-7]. It is achievable because significant power electronic-interfaced converters are acting as voltage source inverters that enables the power converter operates in voltage-controlled mode (VCM) for islanded-mode and current-controlled mode (CCM) during grid-interactive. Henceforth, control strategies also critical impact on power converter interfaced under unbalanced conditions. Theoretically speaking, the MGs controller should be able to determine the accessibility of microgrid operation modes under occurrence of unbalanced loads or weak grids. Thus, the controller mechanism enables the operation of power converter operates either or not accessible in VCM or CCM [8-10]. In VCM, always the inverter yields a controlled output while regulating its amplitude and frequency. On the other hand, CCM adjusts the output current to the reference value and always correlated with the grid synchronization strategies.

The MG's task is to regulate the active and reactive powers generated by the DG units and distribute them according to the load demand. In addition, the surplus power in the microgrid can be exported into the main grid and also can grant essential support to the primary network. In the islanded mode of operation, the microgrid operates as an autonomous entity. Both voltage and frequency are controllable parameters within the DG units, which means that they are no longer supported by the main grid. The active and reactive powers are simultaneously generated within the DG units and accumulated within the microgrid to ensure accurate power load sharing.

There are two definitions of islanding detection: intentional and unintentional islanding. Intentional islanding can be prompted by the scheduled maintenance or when the power quality from the main grid jeopardizes the microgrid operation. Unintentional islanding occurs due to grid faults and unplanned events that are unknown to the microgrid. Hence, an international standard has been established so that microgrids are able to meet several criteria in order to provide reliable ancillary services. The interconnecting of distributed energy resources is stated in IEEE Standards 1547 and 2030 [11-13] so that the transition mode from one state to another can be achieved effectively. For instance, the microgrid can sustain itself when there is a presence of a weak grid and reconnects when the situation is remedied. The assistance of static transfer switch (STS) offers the first action by detecting and disconnecting the microgrid from the grid network, thus guaranteeing continuous power supply to the local loads and protecting the distributed energy source and ESS. 


\section{Contributions and Paper Organization}

The motivation of this paper is to provide a reviewed on various control strategies of the interconnection of microgrid with the main grid from synchronization, frequency, and voltage restoration perspective under balanced and unbalanced grid conditions. An overview of the microgrid multilayer control trends along with their benefits and shortcomings are carried out in order to help researchers to identify appropriate techniques for their products. There are numerous review studies over the years on this subject matter, however, there is a gap in the discussion on the state-of-the-art coordinated controls in the hierarchy level in proportion of their objectives and applications. A comparative studied for the grid synchronization techniques based on phase-locked loop (PLL) and non-PLL, i.e., synchronverter, frequency-locked loop, discrete Fourier transform, weighted least square estimation are comprehensively discussed and surveyed in detail. The performance comparison of various voltage and frequency regulation controller are also investigated and overviewed in order to provide better power sharing capability. With various multilayer controller strategies and applications, therefore, the findings of this paper should be able to categorized and differentiates the diversification of controller strategies in order to bridge the research gap for further study.

This paper comprises five sections. Microgrid topologies are delivered in Section 2. Section 3 presents the multilayer hierarchical controls with coordinated control. Meanwhile, the primary and secondary state-of-the-art controls are discussed in Sections 3.2 and 3.3, respectively. Section 4 presents key features and recommendations for potential further developments. The conclusion is presented in Section 5.

\section{Microgrid Hierarchical Control Group}

It is significantly challenging to identify which control method is adequate, and most commonly, the application predominantly depends on the microgrid's traits. The fundamental control objective in a microgrid topology is to ensure reliable and flexible operation, while maintaining close regulation of the microgrid's voltage and frequency as compulsory targets. In general, there are two main state-of-the-art control principles for a microgrid: centralized and decentralized. A centralized control relies on a set of data collection in a dedicated central controller. It continuously monitors and controls the computation taking action at a single central point for the relevant units via low-bandwidth communication between the central controller unit and the controlled groups [14-16]. In contrast with the centralized approach, the decentralized control requires that all DG units and the ESS have a local controller and operate independently based just on local measurements [17-19]. A valid argument between those controls can be attained within the hierarchical control scheme. In this approach, three control levels are distinguished: primary, secondary, and tertiary [20,21], as depicted in Figure 2 with their respective responsibilities. The primary and secondary controllers are responsible for the islanded mode, while the tertiary control mainly serves and is managed at the grid side.

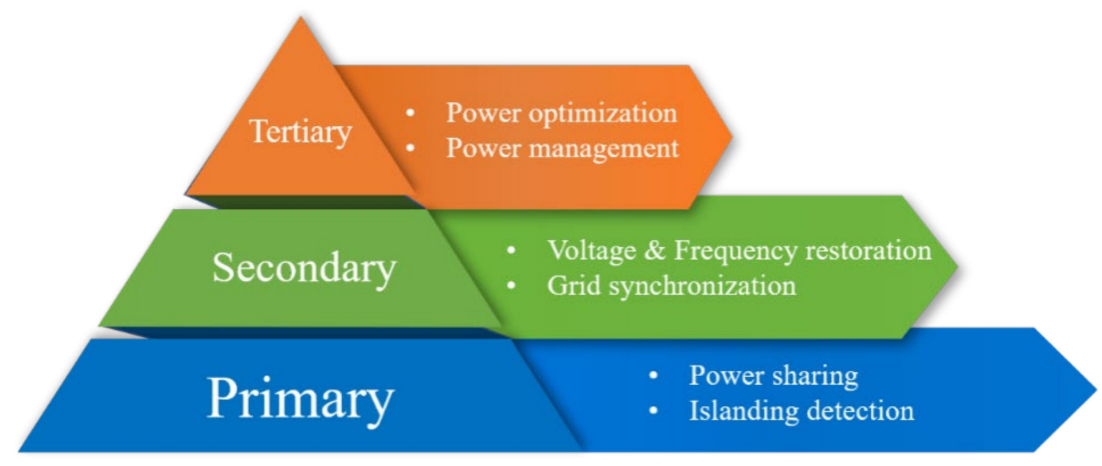

Figure 2. Hierarchical control with respective obligations for each level. 


\subsection{Primary Control}

Also called the internal control or local control, the primary control is defined as the first stage in the control hierarchy group by presenting locally collected information at the fastest response and requires no communication between the controllers. All information are gathered locally and have a certain intelligence level to operate in a decentralized operation mode. According to [22], the decentralized approach should highlight the following fundamental concerns: the integrated units should share the desired total load, stability assurance is provided on a global scope, and the inverter control is capable of providing DC voltage offset avoidance.

The inverter output control's architecture is distinguished from the outer loop for voltage control and internal control for current regulation, as illustrated in Figure 3. The state-of-the-art inner-loop control for the grid-side converter controllers are mainly associated with their reference frames: synchronous frame $(d c)$, stationary frame $(\alpha \beta)$, and natural frame $(a b c)$. The synchronous and stationary reference frames served the $d c$ and sinusoidal variables, respectively, and are associated with the proportional integral (PI)-based controllers and proportional resonant (PR)-based controllers, respectively. Generally, the natural reference frame is employed in the controllers' approach as PI, PR, dead-beat, and hysteresis controls. The use of PI controllers is the most comprehensive method for control loop design [23].

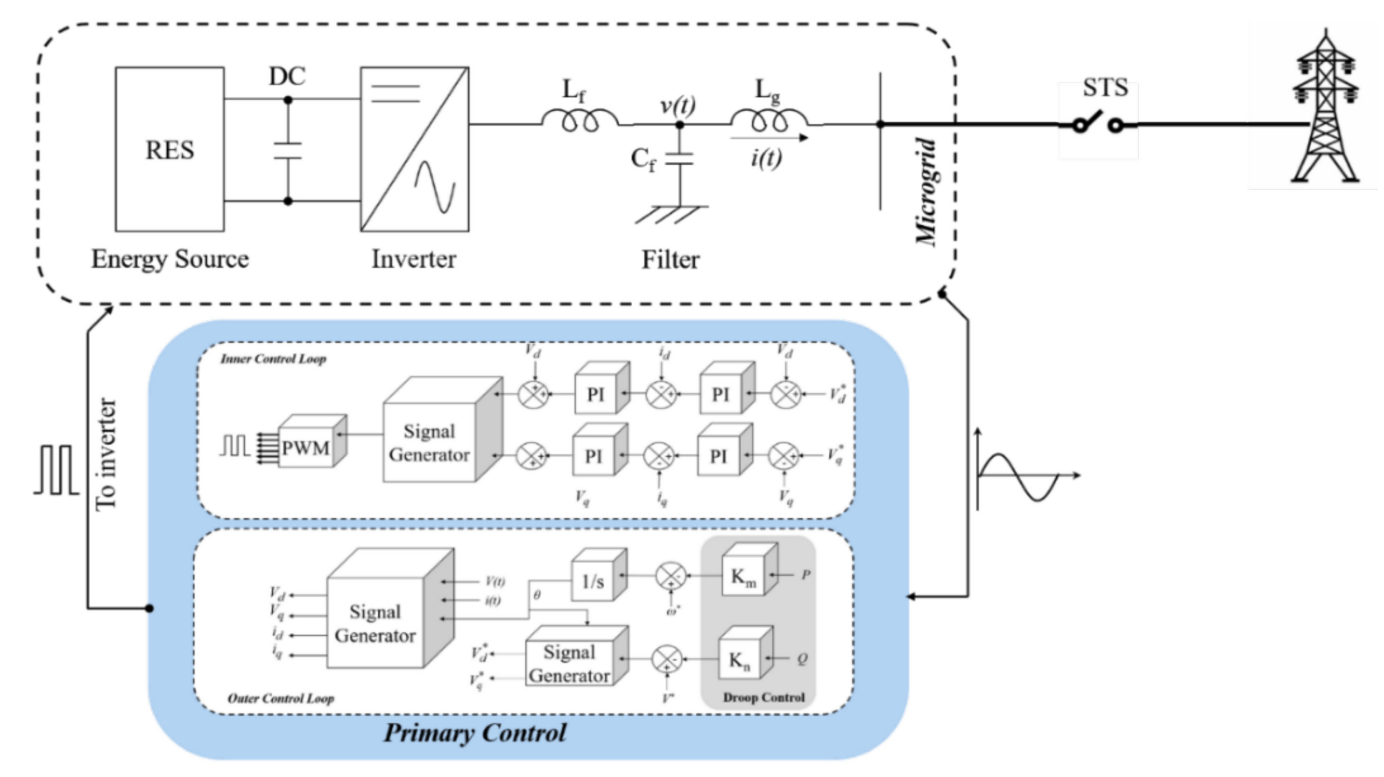

Figure 3. Primary control structure's block diagram.

On the other hand, the state-of-the-art outer loop serves as the power sharing control. This control is significant to control the DG unit as well as the associated local loads to meet the balancing between the active and reactive powers. As for the synchronous generator, three prime components are used to realize the output control and power sharing, which are the voltage regulator, governor, and the inertia obtained from the synchronous machine itself [24]. Droop controllers have been used to emulate the droop traits of the synchronous generator; by purposely simulating the synchronous generator, it has shown the fastest response. It utilizes the correlation of active power-frequency $(P / f)$ and reactive power-voltage $(Q / V)$ by controlling the values of voltage amplitude and frequency to realize power sharing. The droop-based approach attracts a lot of research efforts due to the advantage it provides over other control options, such as the capability of plug-and-play implementation, flexibility due to non-communication network, simple design, etc. From another perspective, a virtual synchronous generator's (VSG) concept also generally being adopted as presented in $[25,26]$. The relationship between power productions and voltage-frequency regulations can be achieved through virtual inertia and damping factor into the control loop that mimics the dynamics of the existing synchronous 
generator. By means the characteristic of the VSG-inverter based is accessible to the main upstream grid system.

In addition, the independency on non-communication control also can be offered as a communication control between the devices and could be applied according to the requirements. Hence, power sharing and voltage regulation could be achieved accurately. Despite adjustment accuracy, communication-link methods can increase the capital cost of microgrids over non-communication methods [27]. Various ways have been presented over the years; for instance, these include master and slave; concentrated control, which has two variants-central limit control and power deviation; instantaneous current sharing; circular chain; and distributed control, among others. Subsequently, the communication-based approach is enormously intricate in extended microgrids and it can degrade system performance during faults at the communication network.

\subsection{Secondary Control}

The secondary hierarchy control level is subject to reliable monitoring, which guarantees and protects the operation of microgrids in both grid-connected and islanded modes. Monitoring the system variables means supervising both voltage amplitude and frequency deviations to make the required adjustments. It is also referred to as the microgrid energy management system (EMS) by regulating the power flow and power quality within the microgrids. The EMS approach can be classified as centralized and decentralized approaches that serve to manage the unpredictability and intermittent of RESs and load demand [28]. The secondary control guarantees that frequency and voltage deviations are controlled near zero within the load variations or generation in the microgrid and serves the power system by rectifying the grid frequency deviations to within permissible limits [16]. For islanded microgrid operation, the secondary control family is considered as the highest rank in the hierarchical level. According to [2,6], the secondary control has a slower behavior in dynamic response when the secondary unit is detached from primary control, which lessens the communication bandwidth by using sampled measurements of the microgrid variables to permit enough time to execute intricate calculations. A central controller is relatively essential to ensure that the power system operates as seamlessly as possible during significant disturbances and during grid synchronization and transition between the microgrid modes (islanded to grid mode and vice versa) as per market requirements. It can be realized by utilizing an external centralized controller to restore permanent voltage and frequency deviations produced by the primary control.

The architecture of the centralized approach consists of a central controller, which delivers pertinent information of each DG unit and load within the microgrid, and the network itself. The implementation of the centralized method allows for the completion of online optimization routines, given that all the relevant information are collected at a sole point. For instance, the measurements of the main grid's frequency and voltage are realized to generate reference signals and are used by the secondary control loop to provide grid-connected operation mode. The optimal dispatch in [29] mainly performs the analyzed offline calculation in terms of cost and system performance in low-voltage microgrids. In addition, at this level, it is significant to interface the DGs and the ESS via master-slave units [30]. Through this approach, all slave converters can be modeled as current sources. In the islanded operation mode, the battery bank itself operates as a master converter that provides the reference voltage and operating frequency for other sources, which act as slave units. Whereas in grid-connected mode, the latter works as master units and serves to provides the reference voltage and frequency to the PCC. The studies in $[31,32]$ has demonstrated the effectiveness of isolated mode control in an islanded microgrid system including PV system, diesel generator, ESS and even tidal turbine. Other approaches include optimal power flow [33] and terminal sliding mode [34], among others, for several feasible scenarios of the microgrid.

On the other hand, the decentralized method is primarily addressed in the microgrid central controller (MGCC) throughout the multi-agent system (MAS) framework. MAS consists of multiple intelligent agents that operate by relying upon local information, which interacts with one another to 
achieve global and local objectives. A comprehensive review of the MAS approach is presented in [35]. Meanwhile, MAS implementation is proposed in [36,37]. An approach in [38] includes an additional agent (fuzzy cognitive maps) to reduce the risk of total system breakdown since a possible failure of some decentralized agents is not distinguished from a total EMS failure.

\subsection{Tertiary Control}

This high rank in the hierarchy control family is primarily associated with the main host grid and generally can be defined as the power flow management according to set points depending on the primary network and is coordinated with the regulations of voltage amplitude and frequency. It is in charge of organizing the operation of multiple microgrids cooperating in the system by measuring the active and reactive power ratio at the PCC, and the comparison of the grid's active and reactive powers against the desired reference values can be realized. The dynamic response of this control is slow in order of several minutes when delivering signals to the secondary level controls at the microgrid and other sub-systems that form the full grid.

According to Figure 4, when the microgrid is operating in grid-tied mode, the power flows can be controlled through frequency adjustment by altering the phase in steady state and the voltage amplitude inside the microgrid [39]. The measured P/Q through the STS, $P_{G}$, and $Q_{G}$ are compared with the desired $P^{*}$ and $Q^{*}$ to obtain the desired reference values. Distribution network operator $(\mathrm{DNO})$ and market operator $(\mathrm{MO})$ are among the multivalent controller approaches. DNO is needed when there are more than one microgrids in the distribution system, whereas $\mathrm{MO}$ is accountable for the microgrid market management; both are part of the primary grid, which means that they are unaccountable for the microgrid management. Henceforth, there will be no further discussion concerning the tertiary control approach.

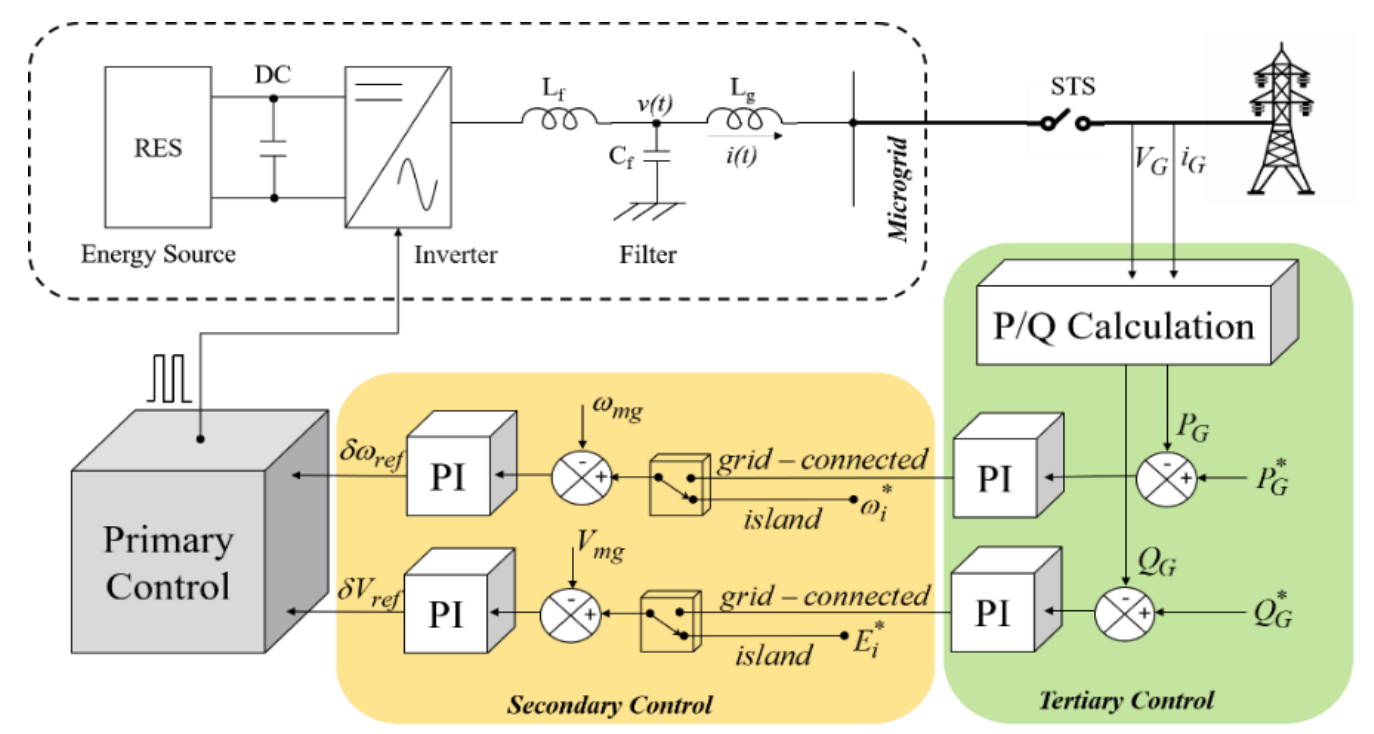

Figure 4. Standard structure's block diagram consisting of secondary and tertiary controls.

\section{Hierarchical State-of-the-Art Control}

This section discusses the microgrid control family. As previously mentioned, the primary control is responsible for providing the current reference signal according to the voltage source inverter (VSI) operation modes, either in VCM or CCM. These characteristics can be determined according to the electrical grid conditions at the PCC. All the different controller approaches significantly provide better steady-state error requirements and improve the disturbance rejection. A brief discussion on the variability methods from the very simple to the sophisticated analytical approaches is presented here. 
However, the primary control permanently causes voltage and frequency variations, which considerably affects the power sharing performance as well as the dynamic response. Other than that, the conventional droop approach does not meet the specific criteria when the parallel system is obligated to share nonlinear load portion because the control units have to consider the harmonic current while, at the same time, retaining the active and reactive powers at the demand level. Henceforth, numerous studies have discussed the secondary control groups to address these inherent issues.

\subsection{Overview of the Inner-Loop Control Methods}

As previously mentioned, the use of power electronic interfaces is able to make the microgrid operate in both islanded and grid-connected modes. Thus, VSI realizes the flexibility of microgrid operation modes by relying upon VCM and CCM behaviors. For instance, VCM is used in islanded mode to maintain the stability of voltage. In contrast, in grid-connected mode, CCM is commonly used to inject current into the primary grid. The inner current loop is mandatory to provide the current reference associated with the external voltage control loop.

- Proportional Integral (PI): The PI method is the most applied over the years to serve different purposes and is practically employed with the synchronous reference frame associated with $d c$ variables. It delivers numerous benefits, such as less complicated controller designs, applicability in linear time-invariant systems, practicability for the single-input-single-output (SISO) system, etc. For instance, [40] discusses the effects of the fractional order of the PI method for load-sharing revamping, and the same method is proposed in [41] and [42] in their respective applications. The PI controller does not solely correspond on the $d c$ variables but also on the sinusoidal variables. As mentioned in [43], the PI current controller integrators associate with the stationary frame under undesirable and distorted operating conditions. It offers low computational burden with zero steady-state error for current harmonics concerns.

- Proportional resonant (PR): A viable alternative to the synchronous frame PI controllers is the stationary frame PR compensators [44]. The PR controller is often interpreted as a sinusoidal controller as it is widely associated with the stationary reference frame $(\alpha \beta)$ as well as the natural reference frame $(a b c)$ due to its capability of forcing errors to be zero and for its harmonics compensation $[45,46]$. Similar methods are proposed in [47] for the distributed power generation systems (DPGS). Studies demonstrate that resonant controllers are an adequate option for inner current control loops to show anticipated performances. It has a high gain around the natural resonant frequency, $\omega$ [48], as it is able to introduce a low-order harmonics compensator to improve the current controller. It offers no excessive computational resources, fast transient performance, and the capability of zero steady-state error at the AC frequency, among others.

- Dead-beat control (DB): Among discrete-time linear controls, dead-beat is the most commonly employed due to its fast transient response in different applications, which makes it a suitable approach for current regulation. The DB control is able to place all the closed-loop poles at zero [49]; thus, the tracking error settles to zero within a few sampling steps equivalent to the SISO systems. Worth mentioning, the DB control is in the predictive family, which forecasts the effect of the control action by tracking the current reference accurately without any error. Some in literature have proposed methods to improve the conventional DB controller's limitations, such as being vulnerable to model uncertainties, sensitive to model and parameter mismatch, etc. For instance, [50,51] employ an adaptive self-tuning for the pulse-width modulated (PWM) converter by adopting a delay compensation caused by voltage calculation, synchronous frame rotation, and the PWM converter itself in order to be homogeneously relocated outside the closed-loop control system, thus compensating for their effects on the closed loop's stability. The implementation of the current controller with a higher degree of disturbance rejection enables swift current tracking with higher bandwidth qualities. In [52], the study uses a combination of a DB controller with neural-network identification to present nonlinear estimation problems and to operate as a grid voltage estimator to realize a grid voltage sensorless scheme to guarantee 
high-quality power injection. However, while the DB controller provides robustness in its performance, its implementation leads to a suffocated control structure.

- Hysteresis control $(H)$ : In the hysteresis approach, the designed controller has to be attached to an adaptive band to achieve fixed switching frequency. The output is the state of the switches that offers variable switching frequency. Worth mentioning, the hysteresis approach is allocated to the predictive control group. Numerous techniques and algorithms to achieve fixed switching frequency are presented in the literature [53-56]. In [57], a hysteresis current regulator is applied for the neutral-point clamped inverter as well as the flying capacitor three-phase inverter, where the measured switched phase-leg voltages are adjusted to the phase leg according to the switching frequency. The hysteresis current regulator is distinguished for its robustness against load variations, for exhibiting high-speed transient performance, and for its simple implementations. Despite the several advantages of the hysteresis controller, it still has drawbacks, such as the high switching frequencies in the inverter due to being interphase-based.

- Predictive control (P): Predictive control is a sophisticated control process satisfying a set of constraints. It uses the system model to forecast the future behavior of the controlled variables. In such a way, it can accurately track the reference current while minimizing the forecasting error within zero error. The model predictive power control (MPPC) and voltage control (MPVC) are proposed in [58]. These schemes can ensure stable DC-bus voltages of BESS as well as a stable AC-bus voltage output and a decent power sharing. Both control schemes provide a simpler control algorithm and better performance. However, the predictive control is prone to network variations. Therefore, in [59], a robust disturbance observer for model predictive control has been proposed for a grid-connected inverter to regulate the current output. The observer is designed to estimate the lumped disturbances (model uncertainties and grid voltage disturbances). An improvement in the reference error tracking is made in [60] by applying an adaptive reference model predictive control to track virtual references rather than actual references. A flexibly modeled virtual multiinput-multi-output (MIMO) generates the error and thus no tuning process is required for different operating points. A seamless transition of mode operations of VSI is presented in [61] through predictive detection and the estimation of control algorithm. It can be achieved through the cost function, thus simplifying the controller's algorithm. The advantage of predictive control design-wise is that it can be implemented more simply depending on the applications. Despite the simple implementation, some predictive controls can be more complicated.

- Sliding mode control (SMC): This control is recognizable by having a robust performance and a fast response time in the variability of system parameters over sizeable operating points [62]. The controller takes vigorous actions if the plant experiences deviations from its average operating point [63]. In such a way, the desired dynamics can be ensured through an essential selection of desired dynamics and control law. However, SMC's performance significantly deteriorates due to the chattering phenomenon in discrete implementation. Therefore, the enhancement of SMC has been made through the output ripple optimization. The works in $[24,64]$ have shown that SMC is employed in the secondary control scheme and is used in both frequency and voltage regulators to enhance power sharing performance and battery charging scheme. SMC shows reliable performance during transients and has better disturbance rejection and low sensitivity to parameter value changes.

- H-infinity control $\left(H_{\infty}\right)$ : The primary task of the $H_{\infty}$ controller is to inject a pure sinusoidal current to the main network in both linear and nonlinear loads even during grid voltage distortions. Reducing the disturbance effect and computation delay is vital to avoid instability in the system caused by the digital control delay. Therefore, active damping is presented in [65] by applying a capacitor current feedback into the controller design process. It not only increases the tracking efficiency but also is able to reduce the harmonic noise in current output. In [66], the study distinguishes the performance of reference signal tracking by showing a minimal number of errors. It is capable of adjusting to the system voltage and frequency equivalent to their nominal values 
after system load variations. As a result, the $H_{\infty}$ scheme offers a robust dynamic performance even in model uncertainties and unbalanced conditions, reduces tracking error, and has an easy implementation.

According to the aforementioned, the comprehensive review on various power, current and voltage control strategies are summarized as advantages and shortcomings in Table 1. A microgrid designer needs to identify which potential method is adequate to suit the application. An efficient control application should provide robust dynamic performance.

Table 1. The advantages and shortcomings of the inner-loop controllers' scheme.

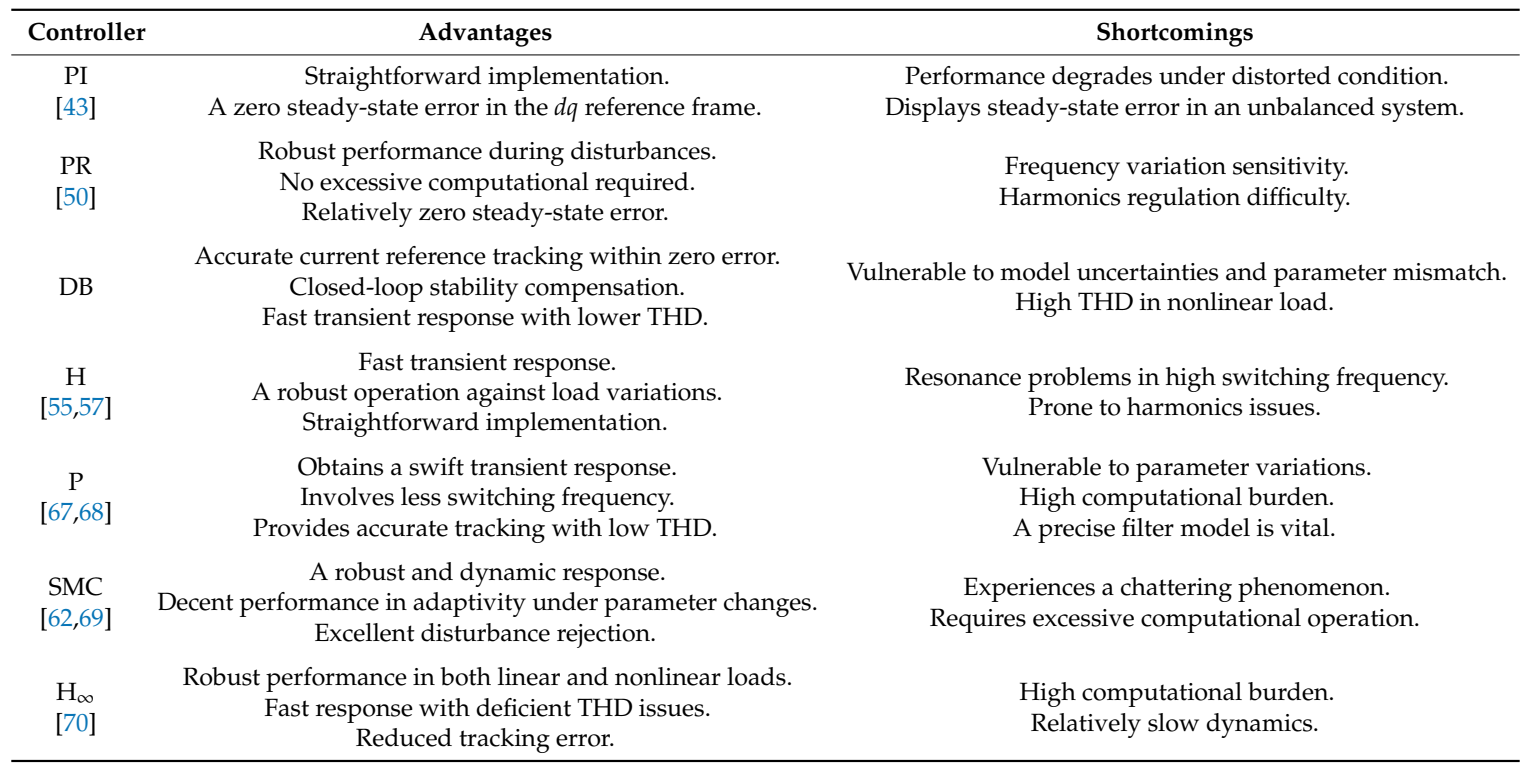

\subsection{Power Sharing for Primary Control}

Power sharing is allocated in the second phase within the primary control level. This control can be ordered depending on whether or not it utilizes the concept of the droop method. Meanwhile, a power sharing control employing a centralized controller belongs to the secondary control [71]. The advantages and drawbacks of each technique are listed in Table 2.

\subsubsection{Droop-Based Control}

The droop-based control method is the most widely applied method to control DG units, as distinguished in the literature $[3,9,72-77]$. The well-established control method is frequency and voltage droop. The main advantage of droop-based control is that it is solely based on local information. Hence, it offers a higher degree of operation in terms of flexibility and reliability. However, the conventional droop control experiences various constraints that could affect the power sharing accuracy among the parallel DG units. These are due to several factors, such as (i) voltage amplitude and frequency deviations, (ii) slow transient response, as it requires low-pass filters (LPF), (iii) vulnerability to nonlinear loads or unbalanced conditions, which introduce circulating currents (harmonic currents), and (iv) the mismatch on the inverter output impedance. Therefore, various research efforts have been presented to counter the inherent limitations of the conventional droop control scheme.

- Virtual output impedance (VI): VI is widely applied to advance the power sharing capability and stability of the system under line mismatch. The inverter output impedance would be in resistive and inductive behaviors. The conventional droop approach in large power systems is entirely operating in inductive line impedance. However, when applied in power electronics, the output impedance relies upon the control strategy used by the inner control loop. In [78], the study demonstrates a robust performance of the inverter with resistive output impedance against 
numerical errors, disturbances, feeder impedance and parameter mismatch by compensating the voltage drop at the load effect and the droop effect itself. As for inductive impedance [79], adaptive droop control is achieved through a self-adjusted VI to provide the decoupling of active and reactive powers, thus guaranteeing accurate power sharing as well as reliable voltage assistance throughout the voltage compensator. A single line-current feedforward control at the voltage reference is widely applied in the conventional VI approach. An enhancement method is presented in [80] to provide VI at both the fundamental and harmonic frequencies by controlling via the DG current loop and the feedforward PCC voltage, respectively. Thus, VI compensates the impacts of the mismatched in the physical feeder impedances and simultaneously achieves precise adjustment of the DG unit's corresponding impedance at both fundamental and selected harmonic frequencies. An adaptive VI proposed in [81] relies upon an extra small injection of AC signal in the output voltage of the parallel inverter to significantly highlight the unbalanced and harmonic power sharing problems caused by the feeder impedance mismatch. Whereas in [82], an adaptive $\mathrm{VI}$ is used for accurate reactive power sharing in an islanded microgrid. The compensation of voltage drop mismatch across the feeders is counteracted by employing communication to facilitate the tuning. In [83], the distributed adaptive VI is employed to suppress large circulating currents caused by the slight differences in both magnitudes and phases in the output voltage of the DG units.

- Adaptive droop $(A D)$ : The current paradigm in autonomous power sharing is by utilizing the voltage deviation in multi-terminal DC (MTDC) grids. The regulation of voltage deviation, as well as frequency deviation, can be realized through the outage stage of the voltage source converter (VSC) and instantaneously performs power sharing. This method is becoming an alternative approach for system planners and operators. In MTDC grids, the AD approach is applied to offer a better performance of the VSC, which enables the sharing of the burden of power mismatch. For instance, $[84,85]$ include frequency support and ensure sufficient power sharing by considering the available headroom of each converter station into the control action. This means that when the VSC relatively achieves the operating point (close to limits), it has the capability to constrain the burden of loss sharing to a great extent to the neighboring converters with higher headroom and spare capacity. The relationship of voltage-current-frequency $(V-I-f)$ characteristics is derived to establish the correlation between frequency and DC voltage. It can adjust its DC voltage reference autonomously according to grid frequency deviation. Hence, it offers the avoidance of overloading and burden in a desirable way. In [86], it is reported that a better dynamic security assessment is performed and autonomous power sharing is provided following the outage of the VSC. It offers stability-constrained adaptive droop gains through the trajectory sensitivity analysis (TSA)-based approach. Meanwhile, the enhancement of power load sharing and the minimization of circulating currents in low-voltage DC microgrid are presented in $[87,88]$. It can be achieved by applying AD resistance and instantaneous virtual resistance shifting to compensate the trade-off between the difference in current sharing and the adaptive voltage positioning. Fast transient response is shown through the right-half-plane zero analysis method, where the stability of the system is guaranteed when the series resistance zero is above the equivalent to right-half-plane zero. The integration of wind farm converters in MTDC grids can be found in [89]. Power sharing improvement and voltage deviation minimization under the presence of any faults and power imbalances in the system can be achieved by employing the voltage droop control with the help of the derated operation of the wind farm converters. It offers control freedom over the active power adjustment and provides ancillary services to the primary grid. In [90], the study integrates a wind farm converter with fuzzy logic-based control. The method can update the droop coefficient through the availability of power capacity of the converters, which revamps the conventional fixed droop coefficient. Through this method, the scheme continuously tracks the dynamic behaviors of the converters and realizes desirable responses under different outage scenarios. As found by the 
authors, the AD scheme ensuring good transient response within proper power sharing, its still experience high computational burden and slow dynamic response.

- Robust droop (RD): An RD controller based on the uncertainty and disturbance estimator (UDE) for the nonaffine nonlinear system is presented in [91-93]. The UDE control algorithm relies upon the assumption that uncertainties and disturbances can be estimated through a filter with an adequate bandwidth. In such a way, the system disturbances and the model nonlinearity can be determined and compensated thoroughly. This method offers a straightforward implementation and does not require inner current control and voltage control schemes. Meanwhile, the regulation of DC-link voltage and robust power sharing in grid-connected VSC-MTDC grids is introduced in [94] by considering the impacts of the droop controller's response, instantaneous power, and DC-side uncertainties. The realization of the controller parameter tuning is through the polynomial method to fix the poles of the equation's trait under possible variations in the droop gain. As a result, it ensures rigid performance under sizeable differences in the converter's operating point to a great extent, as well as under parametric uncertainties and during the occurrence of disturbances. It can increase the system stabilization's effectiveness as well as guaranteeing a robust performance within the system. According to [95], the enhancement of the load voltage drop due to the load and the droop effect can be realized via proportional load sharing. The RD control scheme is integrated with the secondary control. Thus, the load voltage can be retained within the desired range around the nominal value, providing better stability and robustness against disturbances, feeder impedance, and component mismatches. The work in [96] concerns the robust dynamic droop's power sharing for the integration of wind turbines and fuel cells. It employs reverse and direct droop controls, where the reverse droop control is responsible for active and reactive power regulation, while the direct droop control is for the frequency and voltage outputs, which are significantly used for the fuel cells. The adjustment of frequency and voltage within the microgrid can be tracked robustly at specifically designed set points and instantaneously provides better power sharing performance. In the case of a low-inertia wind turbine, a robust control method that is invulnerable against system nonlinearities and changes in the network is reported in [97]. The control scheme exploits multivariable $H_{\infty}$, which integrates with the centralized multi-input-multi-output (MIMO) controller (set reference of active and reactive powers) and the local measurements of active and reactive powers of the droop controllers. The application has excellent power sharing performance against significant disturbances and interconnection operation. In high-voltage microgrid applications, the work in [98] utilizes the signal detection on the high-voltage side of the coupling transformer as the feedback signal. The line impedance is the dominated part of grid impedance (coupling transformer), and hence the impact of line impedance on the power load sharing can be mitigated significantly, especially on the reactive power relationship.

- Feedforward control: An enhanced power flow control is demonstrated in [72] by introducing a feedforward control of the primary grid voltage amplitude and frequency to mitigate the impacts of grid fluctuation on power flow control. It offers improvement in controller stability and provides seamless transitions for grid-connected operation. A similar approach observed in [99] through an adaptive feedforward compensation provides better steady-state power sharing performance while keeping the voltage and frequency regulation. Thus, the robustness of the system stability is enhanced against droop coefficients and network uncertainties.

\subsubsection{Non-Droop-Based Control}

Apart from droop-based methods, various techniques can be applied that may or may not require communication. These techniques are listed below:

- Master and slave: Similarly considered as a secondary control, it consists of a voltage controller for controlling the output voltage to provide a current reference for the other units that assigns the master-slave units. A literature review on this particular method can be found in [30,100-102]. 
The master unit can be defined through a fixed module arbitrarily or based on the maximum current. In the case of a grid-connected mode, the grid itself is presented as the master unit and no specific control is required for grid-connected and islanding operations. For instance, in [103,104], a supplemental control algorithm is proposed to provide speedy response and sophisticated operating conditions for multiple inverters in an autonomous microgrid; thus, the active and reactive powers are shared accurately according to load demands. In [105], a voltage controller is added with a robust controller that is combined with an automatic master control for the precision of output voltage.

- Concentrated control: The operation of this method is based on a central controller by means of a communication link between the central control and the other units. This method consists of the central limit control of power deviation, and their reviews can be found in [106-108]. The current reference value is regulated by the voltage controller. It provides a higher degree of power quality, whether in ideal or transient conditions. However, it requires a high-bandwidth communication link, which increases capital cost.

- Instantaneous power theory (IPT): In [109,110], power sharing could be achieved among parallel DGs devoid of any communication between the devices. An enhancement of IPT is included in [111], which uses a new signal decomposition technique with a great extent of selectivity, thus making it immune to unbalanced and nonlinear power systems. A similar approach in [112] makes the necessary modifications in the fundamental computation to remedy the compensation under any condition of the voltage supply. Another method is presented in [113] for grid-connected VSI under transient conditions, employing an adaptive transformation that instantaneously makes adjustments accordingly to the dynamic voltage conditions, which allows control over constant and oscillating instantaneous power.

- Direct Power Control (DPC): The DPC algorithm has become an alternative for power sharing control, particularly in grid-connected mode of operation. To provide the reference value of power, it solely relies upon the $p-q$ theory to adjust the instantaneous active and reactive power errors and maintaining them within a constant hysteresis band $[114,115]$. Due to the straightforward implementation, it offers several benefits: (1) no grid voltage information is required, as it can be realized through a binary algorithm, (2) compatibility with both sinusoidal and non-sinusoidal voltage signals, and (3) minimal commutation on converter switches.

Following the discussions above, Table 2 addresses the advantages and shortcomings of each control method to deliver an idea that can bridge the gaps among the control approaches. The designed controller should have several features that are immune to the uncertainty model and parametric variations of the microgrid and to load variations. Hence, the advanced algorithms controller complexity can be reduced for further implementation in practical systems. 
Table 2. The advantages and shortcomings of the power sharing control.

\begin{tabular}{|c|c|c|}
\hline Technique & Advantages & Shortcomings \\
\hline $\begin{array}{l}\text { Droop-based } \\
\quad[79,80]\end{array}$ & $\begin{array}{l}\text { Straightforward implementation. } \\
\text { No critical communication line is required. } \\
\text { Significant reliability and flexibility of operations. }\end{array}$ & $\begin{array}{c}\text { Inaccurate power sharing. } \\
\text { Performance degrades under nonlinear load and } \\
\text { unbalanced conditions. } \\
\text { Relatively slow in transient response. }\end{array}$ \\
\hline $\begin{array}{l}\text { Virtual } \\
\text { impedance } \\
{[83,88]}\end{array}$ & $\begin{array}{l}\text { Fast transient response. } \\
\text { Improved current harmonics sharing. } \\
\text { Better output voltage with low THD. } \\
\text { Excellent voltage and frequency regulation. } \\
\text { Better dynamic response. }\end{array}$ & $\begin{array}{l}\text { Relatively poor active and reactive power } \\
\text { sharing performance. } \\
\text { If the line impedance of the parallel inverters is } \\
\text { mismatched, transformation angles will differ and } \\
\text { not be synchronized. }\end{array}$ \\
\hline $\begin{array}{l}\text { Adaptive droop } \\
{[89,90]}\end{array}$ & $\begin{array}{c}\text { Decent transient response. } \\
\text { Good active power sharing. } \\
\text { Compensates circulating current. } \\
\text { Better voltage and frequency adjustment. } \\
\text { Enhances power sharing accuracy and system stability. }\end{array}$ & $\begin{array}{l}\text { Sophisticated implementation. } \\
\text { High computational burden. } \\
\text { Sluggish dynamic response. }\end{array}$ \\
\hline $\begin{array}{l}\text { Robust droop } \\
\quad[97,101]\end{array}$ & $\begin{array}{l}\text { Ensures dynamic stability. } \\
\text { Better voltage and frequency adjustment. } \\
\text { Robust dynamic performance against load variations. }\end{array}$ & $\begin{array}{l}\text { Relatively poor reactive power sharing performance. } \\
\text { Involves high THD in current components. }\end{array}$ \\
\hline $\begin{array}{l}\text { Non-droop- } \\
\text { based } \\
{[106,112,115]}\end{array}$ & $\begin{array}{l}\text { Power sharing enhancement. } \\
\text { Straightforward implementation. } \\
\text { Improves the dynamic stability of power sharing and quality. } \\
\text { Robustness in parametric variation (system and controlled). }\end{array}$ & $\begin{array}{c}\text { Slow dynamic performance. } \\
\text { Performance degrades when communication } \\
\text { malfunctions at a single point. } \\
\text { Communication line increases capital and } \\
\text { maintenance cost. }\end{array}$ \\
\hline
\end{tabular}

\subsection{Voltage and Frequency Restoration for Secondary Control}

As well-known, the deviation of voltage and frequency in the primary droop-based controller in a microgrid is permanent. The secondary control is proposed in the hierarchy level to compensate these deviations. Therefore, numerous approaches have been proposed to enhance the research efforts to tackle this issue by considering whether or not to require a central controller.

1. Centralized controller: The principle of the centralized control approach is identical with the inner loop control, as described in Section 3. As previously mentioned, MGCC is responsible for power management, voltage and frequency regulations, and the interconnection with the utility grid. The tprincipal operations are via a communication link that receives the information from the primary network when operating in grid-connected mode and passing the references value to the primary control level. The studies in $[20,27,66]$ show examples of this approach. They mainly concern the coordination of the control strategy that depends on the communication network to provide a satisfactory operation and power sharing of generation and storage devices. Worth mentioning, all the decision making, collaboration, and prioritization are achieved more efficiently when information is collected at a single point through the central controller. However, the significant weakness in the MGCC approach is the dependency of the regulations on the central controller, which means that the system performance degrades during the presence of a malfunction at a single point of communications in the central controller. Besides, the communication link among devices offers unreliable operation in terms of maintenance and cost considerations.

2. Decentralized controller: A distributed secondary control or MAS network is reportedly a promising method for improving microgrid stability and performance while enhancing the reliability and scalability of the microgrid. The permanent inherent limitations of the primary control, especially the deviations of voltage and frequency, could be counteracted through finite-time and event-triggered control methods, among others.

- Consensus algorithm (CA): CA is widely employed in voltage and frequency regulation schemes, wherein the reference values are distributed among all the primary controllers. The most popular methods are through a distributed cooperative finite-time secondary control $[22,116]$ by employing a neighbor-based linear consensus algorithm that allows each controller to communicate with each other and also by employing the so-called sparse 
communication network. While the consensus of the voltage and frequency set reference values is accomplished over an infinite time horizon with exponential convergence, as in [104,117], the authors apply feedback linearization methods for voltage restoration and finite-time control protocol is used to synchronize frequency to the nominal value, simultaneously achieving accurate active power sharing among the DG units. A similar approach is introduced in [118], which is capable of both restoring $V$-f and guaranteeing reactive power sharing as well. The secondary control under switching communication topology is designed in [119], where MAS network is used for controller stability analysis. A distributed approach offers flexibility and reliability in terms of central control avoidance, which means that the failure of a single unit will not degrade the entire system. Meanwhile, in [120], the restoration of the voltage to the nominal value is realized through the dynamic consensus-based method. The enhancement of flexibility and reliability of the microgrid system is ensured without line impedance consideration.

- Event-triggered: ETC is another approach for data sharing when a condition is fulfilled or an event is triggered, instead of continuously exchanging data among the DGs unit. In such a way, a sampled data is controlled through a designed mechanism [121]. Numerous methods have been proposed in recent years, such as the time-triggered, event-triggered, and self-triggered sampling methods; their reports can be found in [122-124]. ETC makes a computation that relies upon the measurement error and the last event of the variable states. The error is the difference between the measured and the observed values of the variable states. The benefits of ETC is that it is able to maintain superior closed-loop stability and performance while reducing the number of information exchange among the DGs. A centralized ETC can be found in [125], which provides with an auxiliary controller that corresponds to collect all the variable states. It simplifies the number of controller updates. However, the secondary compensation terms in ETC are realized via a pure integrator that compromise a poor transient response.

The comprehensive review of coordinated controller approaches are summarized as advantages and shortcomings in Table 3. As shown, the restoration of voltage and frequency of the microgrid is a vital issue that needs to be confronted to provide excellent service and better power sharing. Notably, voltage and frequency restorations are always incorporated in secondary level group, yet less studies exposed involvement of primary control.

Table 3. Performance comparison of voltage and frequency of secondary control.

\begin{tabular}{|c|c|c|}
\hline Controller & Advantages & Drawbacks \\
\hline $\begin{array}{l}\text { Centralized } \\
{[66]}\end{array}$ & $\begin{array}{l}\text { All the decision making, collaboration, and } \\
\text { prioritization are achieved more efficiently when } \\
\text { information is collected at a single point through the } \\
\text { central controller. } \\
\text { Provides fast and effective process, while retaining } \\
\text { accurate power sharing. }\end{array}$ & $\begin{array}{l}\text { Performance degrades when failure occurs at a single } \\
\text { point of communication. } \\
\text { Communication links among devices offer unreliable } \\
\text { operation in terms of maintenance and } \\
\text { cost considerations. }\end{array}$ \\
\hline $\begin{array}{l}\text { Distributed consensus } \\
{[116,118]}\end{array}$ & $\begin{array}{l}\text { Increases flexibility and reliability of the microgrid } \\
\text { system without taking line impedance consideration. } \\
\text { More reliable and has accurate restorations process. }\end{array}$ & $\begin{array}{l}\text { Sophisticated implementation. } \\
\text { High computational burden. }\end{array}$ \\
\hline $\begin{array}{c}\text { Event-triggered } \\
{[121,123]}\end{array}$ & $\begin{array}{l}\text { Able to maintain superior closed-loop stability } \\
\text { and performance. } \\
\text { Effectively updates voltage and frequency to } \\
\text { nominal values. }\end{array}$ & $\begin{array}{l}\text { High computational burden. } \\
\text { Requires a new switch mechanism, which increases } \\
\text { malfunction factor. }\end{array}$ \\
\hline
\end{tabular}

\section{Grid Synchronization for the Secondary Control Unit}

The purpose of grid synchronization is to monitor and self-regulate the phase to prevent the deviations of voltage and frequency by minimizing the variance in voltage, frequency, and phase angle between the RES AC generators' output and the grid supply [126,127]. The synchronization unit control loop is used to synchronize the microgrid's phase with the grid. Such synchronization 
control entails a cluster of all the controllable DG units employed in the secondary control level in the hierarchical control architecture. It provides relatively zero steady-state errors to be translated into the grid-connected operation mode. Grid synchronization is a subjective subtopic that can be classified into primary or secondary control families. However, in this paper, it is considered as a secondary control. As reported in [115], an ideal synchronization must conform to desirable characteristics such as (i) adeptly tracking the primary grid's phase angle, (ii) effectively tracking variations in the frequency and is immune to disturbance signals and high harmonics parameters, and (iii) fast response to the alterations on the primary grid. Numerous grid synchronization methods have been proposed over the years, either based on phase-locked loop (PLL) or non-PLL methods. On the other hand, synchronization without a dedicated synchronization unit has become an alternative for conventional PLL to provide fast and robust operation and simultaneously reduce the computational burden by nonlinear PLL characteristics. Therefore, numerous proposals for self-synchronization techniques have been presented over the years, as reported in [128-134].

Table 4 address the advantage and disadvantages of grid synchronization with significant methods should be considered to present advanced control techniques that are capable of retaining power quality.

Table 4. The advantages and drawbacks of the grid synchronization techniques.

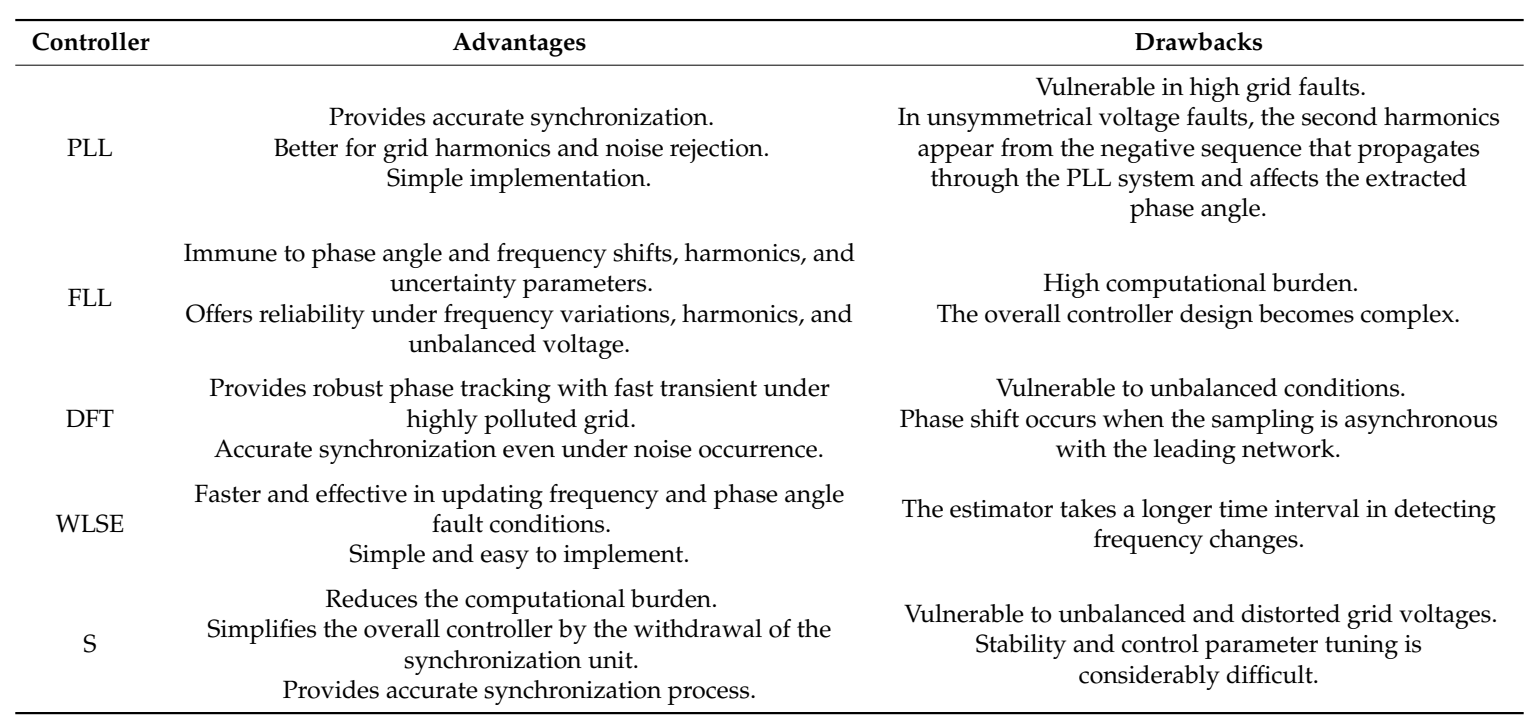

\subsection{Phase-Locked Loop}

Synchronization via PLL is the most widely adopted and is embedded as a dedicated synchronization unit [135-137]. It offers precise tracking of voltage, phase angle, and frequency, and provides simplicity, flexibility, accurate phase angle estimation, etc. However, PLL's performance depreciates when the power converter is integrated into weak grids [138-141]. This scenario is caused by the presence of voltage imbalance and harmonic distortion, double frequency oscillation to the phase error signal, slow dynamic performance, complicated and slow coefficient performance, etc. Numerous modified methods have been presented over the years to mitigate these issues, as shown in [38,134,142-144]. Methods that have been proposed include synchronous reference frame-PLL (SRF-PLL), fixed reference frame PLL (FRF-PLL), enhanced PLL (E-PLL), and second-order generalized integrator PLL (SOGI-PLL), among others.

- SRF-PLL: Studies in [140,145-147] have shown that this technique is the basic scheme in the three-phase system. It offers a rapid and accurate estimation of the phase angle/frequency in ideal grid conditions and offers a straightforward implementation. The operation of SRF-PLL is through the natural frame $(a b c)$ being transformed into the dq reference frame through Park's transformation. Despite fast and accurate phase estimation in ideal conditions, the performance is highly degraded against abrupt shifting in the phase angle as well as double frequency errors in 
negative sequence [148], which are caused by frequency deviation, distorted grid voltage, and the presence of harmonics. Several methods with different techniques and algorithms have been proposed to address these issues: decoupled double SRF-PLL (DDSRF-PLL) [147,149], modified SRF-PLL (MSRF-PLL) [150], and adaptive lattice SRF-PLL (ALSRF-PLL) [151].

- SOGI-PLL: SOGI is widely used in the quadrature signal generator (QSG). Also called quadraturePLL, it seamlessly detects the positive-sequence component to estimate the input signal in-phase and also the quadrature-phase amplitude. Dual SOGI-PLL (DSOGI-PLL) [137,152] corresponds to the transformation of the voltage vectors in the stationary reference frame $(\alpha \beta)$ into QSG, which presents the filtered voltage vector. The positive-sequence voltage vector is obtained via the positive-sequence calculator (PFC), and the q-component is equivalent to zero. As a result, it is able to estimate an accurate phase angle under severe fault conditions such as slow dynamics and large frequency overshoots. On the other hand, a frequency feedback loop is adopted for SOGI resonance frequency under a frequency shift. Some results in [153] demonstrate a rather fast dynamic response and harmonics filter capability. A frequency-fixed SOGI-PLL (FFSOGI-PLL) $[154,155]$ has been introduced to enhance the conventional method by eliminating the frequency feedback loop, thereby increasing the speed and accuracy of the frequency trade-off.

- FRF-PLL: FRF-PLL detects the angular frequency and is used for synchronization purposes instead of for phase angle detection. Thus, the fundamental component is provided in fixed-referenceframe coordinates, including both positive and negative sequences, and makes the assumptions of the angular frequency as an uncertain parameter [156,157]. The operation's performance under unbalanced conditions is reported in $[142,158]$ as being robust against variations in angular frequency and the sag or swells in voltage.

- E-PLL: Using E-PLL, the authors in [159] track the three-phase input signal variables in terms of frequency, amplitude, and phase angle. The fundamental operation is through the extraction of the positive-sequence component of the input signal through an adaptive band-pass filter, as it adjusts the transfer function in proportion to the error signal. It shows a higher degree level of transient response and thus delivers smooth and accurate detection of the fundamental parameters within zero steady-state error. As a result, it provides a robust and precise performance under grid contingencies.

\subsection{Frequency-Locked Loop}

Among recent advancements in grid synchronization for single- and three-phase systems, a new grid synchronization technique has been proposed in [160] called the frequency-locked loop (FLL) technique. This technique is realized in the stationary reference frame and is used to measure the input signal frequency rather than the grid voltage phase. The benefit of this technique is that it does not experience such abrupt phase angle changes. The authors in [161,162] propose the second-order generalized integrator FLL (SOGI-FLL) by implementing two adaptive filters to produce a stationary reference frame that can auto-tune to the grid frequency. This method gives rise to a new structure, called the dual SOGI (DSOGI-FLL), which can estimate the symmetrical components of the grid voltage even under adverse grid conditions. The work in [163] introduces the enhanced FLL (EFLL) for faster dynamic response. This method proposes a generalized design framework of FLL via the Popov hyperstability criterion-based model reference adaptive control. Therefore, a simple structure and convergence speed of the FLL are developed. An adaptive frequency system based on limit cycle oscillator FLL (LCO-FLL) is proposed in [164]. This technique offers a high degree of invulnerability against phase-frequency shifts, harmonics, and voltage sags. Besides, it performs well in a highly polluted grid by ensuring an acceptable transient unto the synchronization process, which achieves the synchrony with the network from any initial condition set. A new multiresonant frequency adaptive synchronization method is proposed in $[134,165]$ that not only can estimate both positive- and negative-sequence components at fundamental frequency but also can detect the following sequence components at harmonic frequencies. This technique uses both harmonious decoupling networks 
of multiple SOGI and FLL, known as MSOGI-FLL. As a result, the system frequency becomes more adaptive in behavior. The benefit of this method is that the tuning process of different harmonics at the fundamental grid frequency can be deduced. Under highly distorted grid conditions, MSOGI-FLL contributes to detecting accurately with less computation time and low computational burden in symmetrical harmonic components.

\subsection{Discrete Fourier Transform (DFT)}

The DFT method is considered as the first method of detecting the frequency and harmonics of the periodic signal [166]. Grid synchronization using DFT analysis is a mathematical tool, which transforms a given function from the time domain to the frequency domain. The authors in $[133,167]$ use recursive adaptive window DFT (RDFT) for power converter line synchronization by means of filtering the received grid voltage. This technique offers a high degree of invulnerability against noise. Still, when the DFT time window does not emulate the grid period, a phase shift arises between the filtered voltage and the grid voltage. Hence, an improved phase-detection via sliding DFT (SDFT) has been proposed in $[168,169]$. This technique displays a robust performance in phase-tracking capability with fast transient response under grid contingencies. This method, which is based on a phase-detection system, is adequate as it requires a lesser amount of operation to obtain a single frequency component. As a result, computational complexity is reduced with a more straightforward implementation than conventional DFT methods. In highly polluted grid conditions, a positive-sequence phase-angle estimation method is presented in [170-172], known as interpolated DFT (IpDFT), which can realize an optimum trade-off between the estimation accuracy and the response time. The proposed technique depends on the obtained sampling rate and can be utilized in the control hierarchy to determine errors and estimate phasors by using analytical analysis, thus generating a one-cycle transient, which is invulnerable to voltage imbalances, harmonics, noises, and grid frequency variations.

\subsection{Weighted Least Square Estimation (WLSE)}

The synchronization technique of WLSE was introduced back in 2000 [173] and is gaining more attention for its robustness against disturbances that may exist in the power grid. This method is able to estimate separately the positive and negative sequences of frequency and phase angle without significant delay and with covariance resetting, especially under sudden voltage sag or unbalanced conditions. However, to estimate more accurate harmonic phasors, especially under the deviations of power and frequency, a phasor estimator that is realized via the merger of the harmonics components is applied in [174]. It offers a better and more efficient update for the unit reference signal matrix, along with frequency tracking. Thus, the phasor can be maintained as a constant when the power grid frequency deviates from the nominal value. Several works have tried to improve the performance of the sparse algorithm when suffering from the presence of transients on the tracked phase. An extension of the least-square-style WLS is proposed in [175], wherein it allows the measurement of the instantaneous frequency value of real signals for single- or three-phase systems. This technique is applied to the decoupling methods, adaptive filtering of input signals, and frequency estimation. It provides more robustness of system frequency because the estimated frequency is computed using the provided information. A much simpler structure that can be implemented recursively is proposed in [132]. This synchronizer technique compares the sampled grid voltages to complement a straight line to emulate the estimation of the grid phase angle. Hence a frequency filter is added to expand the synchronizer performance, thus making it immune when operating in a polluted grid.

\subsection{Synchronverter}

A new concept of synchronization by executing the operation of an inverter that is able to simulate the behavior of a synchronous generator (SG) is developed in [129,176], named a synchronverter (S). A synchronverter comprises the mathematical model of the synchronous machine and acts similarly as SG to deliver the voltage supply [177]. Its controller is on the fundamental level of the 
power controller with an incorporated capacity of voltage and frequency regulation and hence is able to achieve active and reactive power control and voltage and frequency management. An SG is innately ready to synchronize with the power grid; similarly, a synchronverter syncs with the power grid without a synchronization unit because the synchronization function is coordinated in the power controller. This synchronization technique is able to compensate the slow elements present in the closed-loop system consisting of the synchronization unit (PLL), remove the dependency on the inverter controller and the power system, and eliminate the nonlinear factor that influences the accuracy and speed of the synchronization [178]. It broadens the system bandwidth for better analysis and stability, reducing time and increasing the efficiency of synchronization, and considerably enhances the performance of the system, while simultaneously diminishing the complexity of the overall controller. As in [179] the synchronization of the output voltages and frequency is achieved via virtual rotor inertia computations. A modified self-synchronized synchronverter is introduced in [180] for unbalanced conditions in the main grid. This technique can tackle power ripples and balance the grid currents. To achieve these objectives, a resonant controller is used to restrain current harmonics and power ripples. Through the synchronverter scheme, it offers fast response synchronization, accurate phase angle and frequency tracking. Yet the utilization of virtual inertia and damping coefficient might jeopardize the system stability if the selection is inadequate and provide high computational burden.

\section{Possibility Implementation of Frequency Self-Restoration Based on $i$-Droop Function and DER Impacts}

The penetration and utilization of RES entail the environmentally friendly and economical operation of the whole system. Current research works and technologies deliver numerous solutions and prospects to accomplish these objectives in distinct fields. Meanwhile, project-based studies, developments, and integrations demonstrate the suitability and practicability of different methods. However, there are still research gaps in delivering better performance, particularly for the droop-based approach. The functions of the primary control should be further studied to expand functionalities that do not limit the power sharing scope, thus increasing the reliability and flexibility of the whole system. There is still a shortage of studies and reports on the use of droop control for voltage and frequency regulation without relying on secondary control adjustment. The management of variable energy generation and consumption is still challenging, including actively participating at the consumer side. Figure 5 depicts the frequency and voltage self-restoration function that is presented by the authors for an $i$-droop possibility technique. As noticed, the idea is to simplify the controller's structure so that it can reduce the complexity of the whole system control design and perform accurate power sharing, while retaining voltage and frequency at their nominal values. As for the authors' hypothesis, it should consider an integrated controller that can fulfill both operations of frequency restoration at grid synchronization in autonomous way. Theoretically, the operation solely relies upon the local evaluation, which can achieve self-synchronization. Figure 6 exhibits the prediction of self-frequency restoration under load variations suggested by authors.

The requirements for a simple and reliable operation as well as the autonomous coordination strategies of different distributed energy resources (DERs) are gaining more attention. As known, the selection of centralized or decentralized controller techniques has trade-offs between them. Fully decentralized management is proven to offer flexibility enhancement, but a comprehensive analysis is necessary to provide a secure and reliable operation of the system.

Further penetration of RES is anticipated in microgrid systems as they are distinguished as being pollution-free and thus environment-friendly. Henceforth, additional efforts are essential to solving the challenges in $P Q$ issues correlated with RES and grid stability.

Grid synchronization is one of the vital areas in terms of a microgrid's technical challenges, primarily when the microgrid relies upon a dedicated synchronization unit. According to the studies above, there is still a shortage of reports and reviews on the application of artificial intelligence in a microgrid grid-connected synchronization. Significantly, a hybrid method can be initiated with 
other conventional means. In such a way, self-grid synchronization can be realized at fundamental grid frequencies.

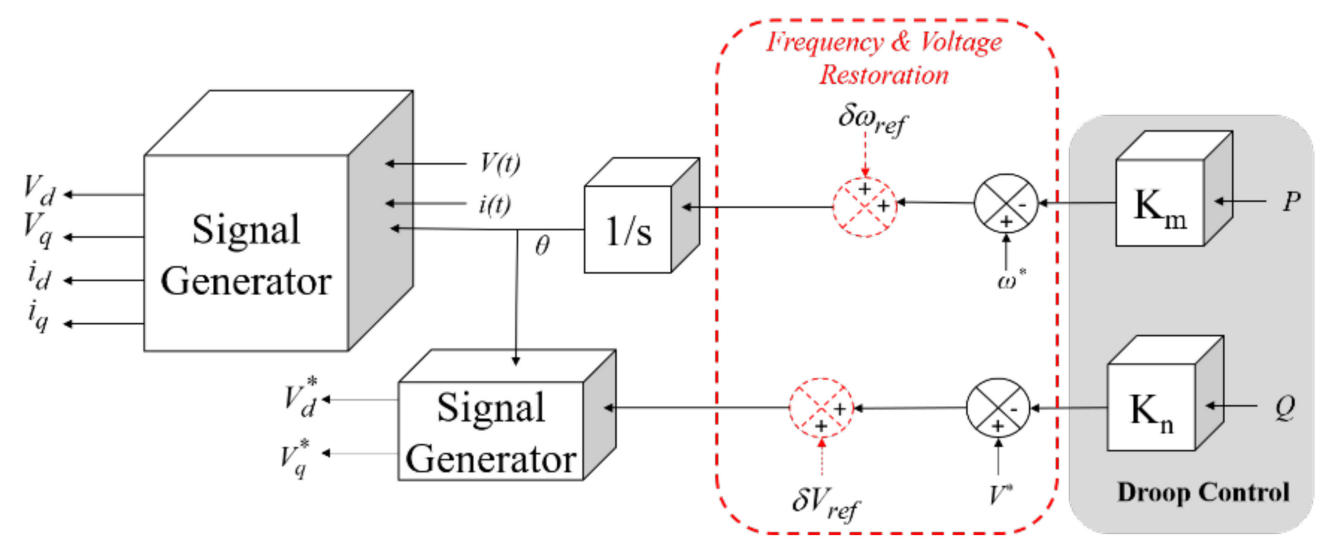

Figure 5. The potential self-restoration function for voltage and frequency in i-droop mode.

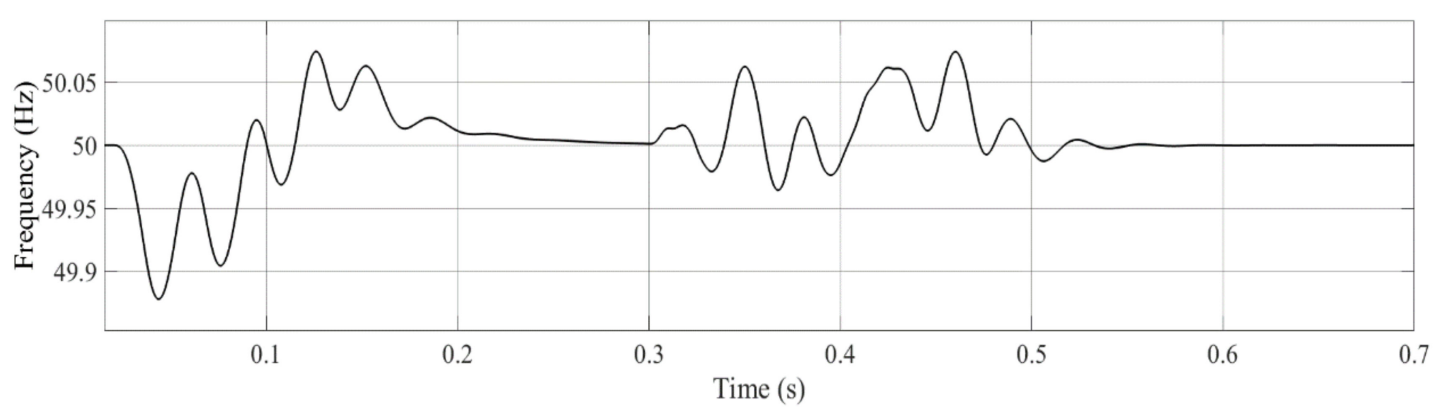

Figure 6. A self-frequency restoration at the fundamental value.

\section{Conclusions}

An ample summary has been delivered in the overview of the trends in the microgrid's state-of-the-art hierarchical control. The presented review exhibits the variability in the coordinated controller schemes in terms of objectives and applications, which is vital in the development of an intelligent microgrid. This review highlights the features of decentralizing and centralize technique, as well as non-communication against communication approach. The primary and secondary level is described showing different operating modes as a hierarchical control strategy, in terms of the comparative study exhibits the advantages and disadvantages of each controller, particularly the inner-loop, power sharing, voltage and frequency restoration, and grid synchronization schemes.

As for the primary control level, the prime responsibility is to realize power sharing, power quality, flexibility, and reliability. It has been concluded that droop-based method is primarily applied due to its simplicity, plug-and-play feature, and no communication-based requirement while ensuring proper power sharing both in islanded and grid-connected modes of operation. However, it suffers from voltage and frequency deviations, which becomes the main drawback that can jeopardize the microgrid's stability and performance. Therefore, numerous schemes have been proposed to overcome the droop-based method's inherent limitations. For instance, virtual impedances, adaptive control, and robust control are control techniques that can deliver accurate reference signals even in an undesirable state. Secondary level techniques have been identified whether or not implements in a centralized or decentralized approach. According to studies, it has been distinguished that a centralized approach are adequate for single-use in low-scale microgrid configurations. In contrast, the decentralized technique are applicable for multiple users at large-scale microgrid systems, with both voltage-frequency restoration and grid synchronization has been presented. Significantly requires to designs the controller that enables synchronization mechanism, which can embed into the controller loop with no dependency on 
PLL unit. Through this study it finds that, there are shortfalls on self-synchronization in decentralized manner that enables voltage and frequency restoration functionality in a manner that resemblance the function of PLL. Henceforth, this concept are recommended for further study.

As aforementioned, the future trends in microgrid technologies are toward advanced decentralized control methods with incorporated an artificial intelligence. The next potential research angles that need to be accomplished for the further evolution of smart microgrids is a straightforward implementation with a robust algorithm in advanced decentralized and self-synchronization techniques suggested by $i$-droop technique that can be a bridge gap for the solution in order to have immunes against undesired conditions. With simple development, less computational involvement and economically wise have becomes an alternative solution for controller designers in order to have fast dynamic response and robustness to high disturbances. Thus, it provides more adequate voltage-frequency self-restoration, fast grid-connection, and yet providing an accurate power sharing that can be seen in next coming papers before the system become fully autonomous.

Funding: This research was funded by UTHM Research Management Centre fund, and Research University Grant Program under grant number H538.

Acknowledgments: The authors would like to give acknowledgement to the Advanced Control in Power Converter research group for essential assistance.

Conflicts of Interest: The authors declare no conflict of interest.

\section{References}

1. Meckling, J.; Sterner, T.; Wagner, G. Policy sequencing toward decarbonization. Nat. Energy 2017, 2, 918-922. [CrossRef]

2. Olivares, D.E.; Mehrizi-Sani, A.; Etemadi, A.H.; Cañizares, C.A.; Iravani, R.; Kazerani, M.; Hajimiragha, A.H.; Gomis-Bellmunt, O.; Saeedifard, M.; Palma-Behnke, R.; et al. Trends in microgrid control. IEEE Trans. Smart Grid 2020, 5, 1905-1919. [CrossRef]

3. Mueller, J.A.; Kimball, J.W. An Efficient Method of Determining Operating Points of Droop-Controlled Microgrids. IEEE Trans. Energy Convers. 2017, 32, 1432-1446. [CrossRef]

4. VanDoorn, T.L.; Meersman, B.; De Kooning, J.D.M.; Vandevelde, L. Transition from Islanded to Grid- Connected Mode of Microgrids with Voltage-Based Droop Control. IEEE Trans. Power Syst. 2013, 28, 2545-2553. [CrossRef]

5. Zhang, D.; Fletcher, J. Operation of Autonomous AC Microgrid at Constant Frequency and with Reactive Power Generation from Grid-forming, Grid-supporting and Grid-feeding Generators. IEEE Proc. TENCON 2019, 10, 1560-1565.

6. Unamuno, E.; Barrena, J.A. Hybrid ac/dc microgrids—Part II: Review and classification of control strategies. Renew. Sustain. Energy Rev. 2015, 52, 1123-1134. [CrossRef]

7. Huang, X.; Wang, K.; Qiu, J.; Hang, L.; Li, G.; Wang, X. Decentralized Control of Multi-Parallel Grid-Forming DGs in Islanded Microgrids for Enhanced Transient Performance. IEEE Access 2019, 7, 17958-17968. [CrossRef]

8. Yoon, S.; Oh, H.; Choi, S. Controller Design and Implementation of Indirect Current Control Based Utility-Interactive Inverter System. IEEE Trans. Power Electron. 2013, 28, 26-30. [CrossRef]

9. Ketabi, A.; Rajamand, S.S.; Shahidehpour, M. Power sharing in parallel inverters with different types of loads. IET Gener. Transm. Distrib. 2017, 11, 2438-2447. [CrossRef]

10. Ochs, D.S.; Mirafzal, B.; Sotoodeh, P. A Method of Seamless Transitions Between Grid-Tied and Stand-Alone Modes of Operation for Utility-Interactive Three-Phase Inverters. IEEE Trans. Ind. Appl. 2014, 50, 1934-1941. [CrossRef]

11. Mariam, L.; Basu, M.; Conlon, M.F. Microgrid: Architecture, policy and future trends. Renew. Sustain. Energy Rev. 2016, 64, 477-489. [CrossRef]

12. IEEE Standards Coordinating Committee 21. IEEE Standards 1547 for Interconnecting Distributed Resources with Electric Power Systems; The Institute of Electrical and Electronic Engineers: New York, NY, USA, 2003.

13. Basso, T. IEEE 1547 and 2030 Standards for Distributed Energy Resources Interconnection and Interoperability with the Electricity Grid; National Renewable Energy Laboratory: Golden, CO, USA, 2014. 
14. Colet, A.; Alvarez-Cuevas-Figuerola, F.; Ruiz-Alvarez, A.; Gomis-Bellmunt, O.; Sudria-Andreu, A. Centralized and Distributed Active and Reactive Power Control of a Utility Connected Microgrid Using IEC61850. IEEE Syst. J. 2011, 6, 58-67. [CrossRef]

15. Tsikalakis, A.G.; Hatziargyriou, N.D. Centralized Control for Optimizing Microgrids Operation. IEEE Transf. Energy Convert. 2011, 23, 1-8.

16. Olivares, D.E.; Canizares, C.A.; Kazerani, M. A centralized optimal energy management system for microgrids. In Proceedings of the 2011 IEEE Power and Energy Society General Meeting, Detroit, MI, USA, 24-28 July 2011; pp. 1-6. [CrossRef]

17. Cai, H.; Xiang, J.; Chen, M.Z.Q.; Wei, W. A decentralized control strategy for photovoltaic sources to unify MPPT and DC-bus voltage regulation. In Proceedings of the 2017 American Control Conference (ACC), Seattle, WA, USA, 24-26 May 2017; Volume 5090, pp. 1-6. [CrossRef]

18. De Matos, J.G.; Silva, F.S.F.; Ribeiro, L.A.D.S. Power Control in AC Isolated Microgrids with Renewable Energy Sources and Energy Storage Systems. IEEE Trans. Ind. Electron. 2015, 62, 3490-3498.

19. Wu, D.; Tang, F.; Dragicevic, T.; Vasquez, J.C.; Guerrero, J.M. Autonomous Active Power Control for Islanded AC Microgrids with Photovoltaic Generation and Energy Storage System. IEEE Trans. Energy Convers. 2014, 29, 882-892. [CrossRef]

20. Guerrero, J.M.; Vasquez, J.C.; Matas, J.; De Vicuña, L.G.; Castilla, M. Hierarchical control of droop-controlled AC and DC microgrids-A general approach toward standardization. IEEE Trans. Ind. Electron. 2011, 58, 158-172. [CrossRef]

21. Meng, L.; Shafiee, Q.; Trecate, G.F.; Karimi, H.; Fulwani, D.; Lu, X.; Guerrero, J.M. Review on Control of DC Microgrids and Multiple Microgrid Clusters. IEEE J. Emerg. Sel. Top. Power Electron. 2017, 5, 928-948.

22. Guerrero, J.M.; Chandorkar, M.; Lee, T.-L.; Loh, P.C. Advanced Control Architectures for Intelligent Microgrids-Part I: Decentralized and Hierarchical Control. IEEE Trans. Ind. Electron. 2013, 60, 1254-1262. [CrossRef]

23. Timbus, A.; Liserre, M.; Teodorescu, R.; Rodriguez, P.; Blaabjerg, F. Evaluation of Current Controllers for Distributed Power Generation Systems. IEEE Trans. Power Electron. 2009, 24, 654-664. [CrossRef]

24. Yan, X.; Cui, Y. Control Method of Parallel Inverters with Self-Synchronizing Characteristics in Distributed Microgrid. Energies 2019, 12, 3871. [CrossRef]

25. Yao, G.; Lu, Z.; Wang, Y.; Benbouzid, M.; Moreau, L. A Virtual Synchronous Generator Based Hierarchical Control Scheme of Distributed Generation Systems. Energies 2017, 10, 2049. [CrossRef]

26. El Tawil, T.; Yao, G.; Charpentier, J.F.; Benbouzid, M. Design and analysis of a virtual synchronous generator control strategy in microgrid application for stand-alone sites. IET Gener. Transm. Distrib. 2019, 13, $2154-2161$. [CrossRef]

27. Agundis-Tinajero, G.; Segundo-Ramírez, J.; Visairo-Cruz, N.; Savaghebi, M.; Guerrero, J.M.; Barocio, E. Power flow modeling of islanded AC microgrids with hierarchical control. Int. J. Electr. Power Energy Syst. 2019, 105, 28-36. [CrossRef]

28. Zia, M.F.; Elbouchikhi, E.; Benbouzid, M. Microgrids energy management systems: A critical review on methods, solutions, and prospects. Appl. Energy 2018, 222, 1033-1055. [CrossRef]

29. Hernandez-Aramburo, C.; Green, T.; Mugniot, N. Fuel Consumption Minimization of a Microgrid. IEEE Trans. Ind. Appl. 2005, 41, 673-681. [CrossRef]

30. Almada, J.; Leão, R.P.; Sampaio, R.; Barroso, G.C. A centralized and heuristic approach for energy management of an AC microgrid. Renew. Sustain. Energy Rev. 2016, 60, 1396-1404. [CrossRef]

31. Belila, A.; Benbouzid, M.; Berkouk, E.; Amirat, Y. On Energy Management Control of a PV-Diesel-ESS Based Microgrid in a Stand-Alone Context. Energies 2018, 11, 2164. [CrossRef]

32. Zia, M.F.; Elbouchikhi, E.; Benbouzid, M.; Guerrero, J.M. Energy Management System for an Islanded Microgrid With Convex Relaxation. IEEE Trans. Ind. Appl. 2019, 55, 7175-7185. [CrossRef]

33. Ye, P.; Sun, B.; Yang, B.; Huang, X.; Sun, F. An optimal power flow based algorithm for coordinated secondary voltage control. In Proceedings of the 2009 Asia-Pacific Power and Energy Engineering Conference, Wuhan, China, 27-31 March 2009; pp. 1-4.

34. Shotorbani, A.M.; Ghassem-Zadeh, S.; Mohammadi-Ivatloo, B.; Hosseini, S.H. A distributed secondary scheme with terminal sliding mode controller for energy storages in an islanded microgrid. Int. J. Electr. Power Energy Syst. 2017, 93, 352-364. [CrossRef] 
35. Han, Y.; Zhang, K.; Li, H.; Coelho, E.A.A.; Guerrero, J.M. MAS-Based Distributed Coordinated Control and Optimization in Microgrid and Microgrid Clusters: A Comprehensive Overview. IEEE Trans. Power Electron. 2018, 33, 6488-6508. [CrossRef]

36. Dimeas, A.L.; Hatziargyriou, N.D. Operation of a Multiagent System for Microgrid Control. IEEE Trans. Power Syst. 2005, 20, 1447-1455. [CrossRef]

37. Logenthiran, I.; Naayagi, R.T.; Woo, W.L.; Phan, V.T.; Abidi, K. Intelligent Control System for Microgrids Using Multiagent System. IEEE J. Emerg. Sel. Top. Power Electron. 2015, 3, 1036-1045. [CrossRef]

38. Karavas, C.-S.; Kyriakarakos, G.; Arvanitis, K.G.; Papadakis, G. A multi-agent decentralized energy management system based on distributed intelligence for the design and control of autonomous polygeneration microgrids. Energy Convers. Manag. 2015, 103, 166-179. [CrossRef]

39. Etxegarai, A.; Eguia, P.; Torres, E.; Iturregi, A.; Valverde, V. Review of grid connection requirements for generation assets in weak power grids. Renew. Sustain. Energy Rev. 2015, 41, 1501-1514. [CrossRef]

40. Zolfaghari, M.; Arani, A.A.K.; Gharehpetian, G.B.; Abedi, M. A fractional order proportional-integral controller design to improve load sharing between DGs in microgrid. In Proceedings of the 2016 Smart Grids Conference (SGC), Kerman, Iran, 20-21 December 2016; pp. 25-29.

41. Arafat, M.N.; Palle, S.; Sozer, Y.; Husain, I. Transition control strategy between standalone and grid-connected operations of voltage-source inverters. IEEE Trans. Ind. Appl. 2012, 48, 1516-1525. [CrossRef]

42. Vidal, A.; Yepes, A.G.; Freijedo, F.D.; Lopez, O.; Malvar, J.; Baneira, F.; Doval-Gandoy, J. A Method for Identification of the Equivalent Inductance and Resistance in the Plant Model of Current-Controlled Grid-Tied Converters. IEEE Trans. Power Electron. 2015, 30, 7245-7261. [CrossRef]

43. Yuan, X.; Allmeling, J.; Merk, W.; Stemmler, H. Stationary frame generalized integrators for current control of active power filters with zero steady state error for current harmonics of concern under unbalanced and distorted operation conditions. IEEE Trans. Ind. Appl. 2002, 38, 523-532. [CrossRef]

44. Holmes, D.G.; Lipo, T.A.; McGrath, B.P.; Kong, W.Y. Optimized Design of Stationary Frame Three Phase AC Current Regulators. IEEE Trans. Power Electron. 2009, 24, 2417-2426. [CrossRef]

45. Teodorescu, R.; Blaabjerg, F.; Liserre, M.; Loh, P. Proportional-resonant controllers and filters for grid-connected voltage-source converters. IEE Proc. Electron. Power Appl. 2006, 153, 750. [CrossRef]

46. Lenwari, W. Optimized design of modified proportional-resonant controller for current control of active filters. In Proceedings of the 2013 IEEE International Conference on Industrial Technology (ICIT), Cape Town, South Africa, 25-28 February 2013; Volume 9, pp. 1-6. [CrossRef]

47. Vidal, A.; Freijedo, F.D.; Yepes, A.G.; Fernandez-Comesana, P.; Malvar, J.; Lopez, Ó.; Doval-Gandoy, J. Assessment and Optimization of the Transient Response of Proportional-Resonant Current Controllers for Distributed Power Generation Systems. IEEE Trans. Ind. Electron. 2012, 60, 1367-1383. [CrossRef]

48. Zhao, W.; Lu, D.D.C.; Agelidis, V.G. Current control of grid-connected boost inverter with zero steady-state error. IEEE Trans. Power Electron. 2011, 26, 2825-2834. [CrossRef]

49. Lim, J.S.; Park, C.; Han, J.; Lee, Y.I.; Lim, J.S.; Park, C.; Han, J.; Lee, Y.I. Robust Tracking Control of a Three-Phase DC-AC Inverter for UPS Applications. IEEE Trans. Ind. Electron. 2013, 61, 4142-4151. [CrossRef]

50. Mohamed, Y.A.-R.I.; El-Saadany, E.F. An Improved Deadbeat Current Control Scheme with a Novel Adaptive Self-Tuning Load Model for a Three-Phase PWM Voltage-Source Inverter. IEEE Trans. Ind. Electron. 2007, 54, 747-759. [CrossRef]

51. Mohamed, Y.A.-R.I.; Rahman, M.A.; Seethapathy, R. Robust Line-Voltage Sensorless Control and Synchronization of LCL-Filtered Distributed Generation Inverters for High Power Quality Grid Connection. IEEE Trans. Power Electron. 2012, 27, 87-98. [CrossRef]

52. Mohamed, Y.A.-R.I.; El-Saadany, E.F. Adaptive Discrete-Time Grid-Voltage Sensorless Interfacing Scheme for Grid-Connected DG-Inverters Based on Neural-Network Identification and Deadbeat Current Regulation. IEEE Trans. Power Electron. 2008, 23, 308-321. [CrossRef]

53. Mohseni, M.; Islam, S.M. A New Vector-Based Hysteresis Current Control Scheme for Three-Phase PWM Voltage-Source Inverters. IEEE Trans. Power Electron. 2010, 25, 2299-2309. [CrossRef]

54. Rahman, K.M.; Khan, M.R.; Choudhury, M.A.; Rahman, M. Variable-band hysteresis current controllers for PWM voltage-source inverters. IEEE Trans. Power Electron. 1997, 12, 964-970. [CrossRef]

55. Tilli, A.; Tonielli, A. Sequential design of hysteresis current controller for three-phase inverter. IEEE Trans. Ind. Electron. 1998, 45, 771-781. [CrossRef] 
56. Dey, A.; Rajeevan, P.; Biju, K.; Mathew, K.; Gopakumar, K. A Space-Vector-Based Hysteresis Current Controller for a General n-Level Inverter-Fed Drive with Nearly Constant Switching Frequency Control. IEEE Trans. Ind. Electron. 2012, 60, 1989-1998. [CrossRef]

57. Davoodnezhad, R.; Holmes, D.G.; McGrath, B. A Novel Three-Level Hysteresis Current Regulation Strategy for Three-Phase Three-Level Inverters. IEEE Trans. Power Electron. 2013, 29, 6100-6109. [CrossRef]

58. Shan, Y.; Hu, J.; Li, Z.; Guerrero, J.M. A Model Predictive Control for Renewable Energy Based AC Microgrids without Any PID Regulators. IEEE Trans. Power Electron. 2018, 33, 9122-9126. [CrossRef]

59. Nam, N.N.; Choi, M.; Lee, Y.I. Model Predictive Control of a Grid-Connected Inverter with LCL Filter using Robust Disturbance Observer. IFAC PapersOnLine 2019, 52, 135-140. [CrossRef]

60. Yang, Y.; Tan, S.-C.; Hui, S.Y.R. Adaptive Reference Model Predictive Control with Improved Performance for Voltage-Source Inverters. IEEE Trans. Control Syst. Technol. 2018, 26, 724-731. [CrossRef]

61. Li, X.; Zhang, H.; Shadmand, M.B.; Balog, R.S. Model Predictive Control of a Voltage-Source Inverter with Seamless Transition between Islanded and Grid-Connected Operations. IEEE Trans. Ind. Electron. 2017, 64, 7906-7918. [CrossRef]

62. Abdelmadjid, G.; Seghir, B.M.; Ahmed, S.; Messlem, Y.; Safa, A. Sensorless Sliding Mode Vector Control of Induction Motor Drives. Int. J. Power Electron. Drive Syst. 2012, 2, 277-284. [CrossRef]

63. Han, Y.; Ma, R.; Cui, J. Adaptive Higher-Order Sliding Mode Control for Islanding and Grid-Connected Operation of a Microgrid. Energies 2018, 11, 1459. [CrossRef]

64. Safa, A.; Berkouk, E.M.; Messlem, Y.; Gouichiche, A. A robust control algorithm for a multifunctional grid tied inverter to enhance the power quality of a microgrid under unbalanced conditions. Int. J. Electr. Power Energy Syst. 2018, 100, 253-264. [CrossRef]

65. Jin, W.; Li, Y.; Sun, G.; Bu, L. Ho Repetitive Control Based on Active Damping with Reduced Computation Delay for LCL-Type Grid-Connected Inverters. Energies 2017, 10, 586. [CrossRef]

66. Sedhom, B.E.; Hatata, A.Y.; El-Saadawi, M.M.; Abd-Raboh, E.-H.E.; Elkis, B.; Abd-Rabo, H. Robust adaptive $\mathrm{H}$-infinity based controller for islanded microgrid supplying non-linear and unbalanced loads. IET Smart Grid 2019, 2, 420-435. [CrossRef]

67. Parisio, A.; Rikos, E.; Glielmo, L. A Model Predictive Control Approach to Microgrid Operation Optimization. IEEE Trans. Control. Syst. Technol. 2014, 22, 1813-1827. [CrossRef]

68. Cortés, P.; Kazmierkowski, M.P.; Kennel, R.M.; Quevedo, D.E.; Rodriguez, J. Predictive control in power electronics and drives. IEEE Trans. Ind. Electron. 2008, 55, 4312-4324. [CrossRef]

69. Mokhtar, M.; Marei, M.I.; El-Sattar, A.A. An Adaptive Droop Control Scheme for DC Microgrids Integrating Sliding Mode Voltage and Current Controlled Boost Converters. IEEE Trans. Smart Grid 2019, 10, 1685-1693. [CrossRef]

70. Hornik, T.; Zhong, Q.-C. A Current-Control Strategy for Voltage-Source Inverters in Microgrids Based on $H^{\infty}$ and Repetitive Control. IEEE Trans. Power Electron. 2011, 26, 943-952. [CrossRef]

71. Vandoorn, T.L.; Guerrero, J.M.; De Kooning, D.M.; Vasquez, J.C.; Vandevelde, L. Decentralized and centralized control of islanded microgrids including reserve management. IEEE Ind. Electron. Mag. 2013, 7, 42-55. [CrossRef]

72. Deng, Y.; Tao, Y.; Chen, G.; Li, G.; He, X. Enhanced Power Flow Control for Grid-Connected Droop-Controlled Inverters with Improved Stability. IEEE Trans. Ind. Electron. 2016, 64, 5919-5929. [CrossRef]

73. Sampaio, L.P.; De Brito, M.A.G.; Alves, M.G.; E Melo, G.A.; Canesin, C.A. Robust control applied to power flow control in single-phase inverter with LCL filter, using droop control and D-stability. In Proceedings of the 2012 10th IEEE/IAS International Conference on Industry Applications, Fortaleza, Brazil, 5-7 November 2012; pp. 1-8.

74. Anand, S.; Fernandes, B.G.; Guerrero, J.M. Distributed Control to Ensure Proportional Load Sharing and Improve Voltage Regulation in Low-Voltage DC Microgrids. IEEE Trans. Power Electron. 2013, 28, 1900-1913. [CrossRef]

75. Jackson, R.; Zulkifli, S.A.; Sham, N.M.B. Power Flow Control Scheme for Hybrid Single-Phase Energy System Using Droop Control: A Comprehensive Survey. Int. Rev. Electr. Eng. 2018, 13, 305. [CrossRef]

76. Ding, G.; Gao, F.; Li, R.; Wu, B. A Communicationless PCC Voltage Compensation Using an Improved Droop Control Scheme in Islanding Microgrids. J. Power Electron. 2017, 17, 294-304. [CrossRef] 
77. Shuvra, M.; Chowdhury, B. Autonomous control of smart inverters in grid connected and islanded mode. In Proceedings of the 2017 IEEE Power \& Energy Society Innovative Smart Grid Technologies Conference (ISGT), Washington, DC, USA, 23-26 April 2017; pp. 1-5.

78. Li, Y.W.; Kao, C.N. An Accurate Power Control Strategy for Power-Electronics-Interfaced Distributed Generation Units Operating in a Low-Voltage Multibus Microgrid. IEEE Trans. Power Electron. 2009, 24, 2977-2988. [CrossRef]

79. Lu, Z.; Li, W.; Li, Z.; Chen, X.; Lu, H.H.C.; Dong, N.; Liu, X. Adaptive droop control with self-adjusted virtual impedance for three-phase inverter under unbalanced conditions. In Proceedings of the 2017 IEEE International Symposium on Circuits and Systems (ISCAS), Baltimore, MD, USA, 28-31 May 2017; pp. 6-9. [CrossRef]

80. He, J.; Li, Y.W.; Guerrero, J.M.; Blaabjerg, F.; Vasquez, J.C. An Islanding Microgrid Using Enhanced Virtual Impedance Control Scheme. IEEE Trans. Power Electron. 2013, 28, 5272-5282. [CrossRef]

81. Liu, B.; Liu, Z.; Liu, J.; An, R.; Zheng, H.; Shi, Y. An Adaptive Virtual Impedance Control Scheme Based on Small-AC-Signal Injection for Unbalanced and Harmonic Power Sharing in Islanded Microgrids. IEEE Trans. Power Electron. 2019, 34, 12333-12355. [CrossRef]

82. Mahmood, H.; Michaelson, D.; Jiang, J. Accurate Reactive Power Sharing in an Islanded Microgrid Using Adaptive Virtual Impedances. IEEE Trans. Power Electron. 2015, 30, 1605-1617. [CrossRef]

83. Kim, S.; Han, J.; Sun, Q. Consensus-based improved droop control for suppressing circulating current using adaptive virtual impedance in microgrids. In Proceedings of the 2016 Chinese Control and Decision Conference (CCDC), Yinchuan, China, 28-30 May 2016; pp. 4473-4478.

84. Wang, W.; Li, Y.; Cao, Y.; Haeger, U.; Rehtanz, C. Adaptive Droop Control of VSC-MTDC System for Frequency Support and Power Sharing. IEEE Trans. Power Syst. 2017, 33, 1264-1274. [CrossRef]

85. Chaudhuri, N.R.; Chaudhuri, B. Adaptive droop control for effective power sharing in multi-terminal DC (MTDC) grids. IEEE Trans. Power Syst. 2013, 28, 21-29. [CrossRef]

86. Yogarathinam, A.; Chaudhuri, N.R. Stability-Constrained Adaptive Droop for Power Sharing in AC-MTDC Grids. IEEE Trans. Power Syst. 2019, 34, 1955-1965. [CrossRef]

87. Huang, H.-H.; Hsieh, C.-Y.; Liao, J.-Y.; Chen, K.-H. Adaptive Droop Resistance Technique for Adaptive Voltage Positioning in Boost DC-DC Converters. IEEE Trans. Power Electron. 2010, 26, 1920-1932. [CrossRef]

88. Augustine, S.; Mishra, M.K.; Lakshminarasamma, N. Adaptive Droop Control Strategy for Load Sharing and Circulating Current Minimization in Standalone DC Low-voltage Microgrid. IEEE Trans. Energy Convers. 2015, 6, 132-141. [CrossRef]

89. Kumar, A.S.; Padhy, B. An Adaptive Droop Control Strategy forAutonomous Power Sharing and DC Voltage Control in Wind Farm-MTDC grids. IET Renew. Power Gener. 2019, 13, 3180-3190. [CrossRef]

90. Chen, X.; Wang, L.; Sun, H.; Chen, Y. Fuzzy Logic Based Adaptive Droop Control in Multiterminal HVDC for Wind Power Integration. IEEE Trans. Energy Convers. 2017, 32, 1200-1208. [CrossRef]

91. Zhong, Q.-C.; Wang, Y.; Ren, B. UDE-Based Robust Droop Control of Inverters in Parallel Operation. IEEE Trans. Ind. Electron. 2017, 64, 7552-7562. [CrossRef]

92. Wang, Y.; Ren, B.; Zhong, Q.-C. Robust Power Flow Control of Grid-Connected Inverters. IEEE Trans. Ind. Electron. 2016, 63, 6887-6897. [CrossRef]

93. Ren, B.; Zhong, Q.-C.; Chen, J. Robust Control for a Class of Nonaffine Nonlinear Systems Based on the Uncertainty and Disturbance Estimator. IEEE Trans. Ind. Electron. 2015, 62, 5881-5888. [CrossRef]

94. Davari, M.; Mohamed, Y.A.-R.I. Robust Droop and DC-Bus Voltage Control for Effective Stabilization and Power Sharing in VSC Multiterminal DC Grids. IEEE Trans. Power Electron. 2017, 33, 4373-4395. [CrossRef]

95. Zhong, Q.-C. Robust Droop Controller for Accurate Proportional Load Sharing Among Inverters Operated in Parallel. IEEE Trans. Ind. Electron. 2013, 60, 1281-1290. [CrossRef]

96. Roozbehani, S.; Hagh, M.T.; Zadeh, S.G. Frequency control of islanded wind-powered microgrid based on coordinated robust dynamic droop power sharing. IET Gener. Transm. Distrib. 2019, 13, 4968-4977. [CrossRef]

97. Hossain, J.; Pota, H.R.; Mahmud, M.A.; Aldeen, M. Robust Control for Power Sharing in Microgrids with Low-Inertia Wind and PV Generators. IEEE Trans. Sustain. Energy 2015, 6, 1067-1077. [CrossRef]

98. Shuai, Z.; Mo, S.; Wang, J.; Shen, Z.J.; Tian, W.; Feng, Y. Droop control method for load share and voltage regulation in high-voltage microgrids. J. Mod. Power Syst. Clean Energy 2016, 4, 76-86. [CrossRef]

99. Delghavi, M.B.; Yazdani, A. An Adaptive Feedforward Compensation for Stability Enhancement in Droop-Controlled Inverter-Based Microgrids. IEEE Trans. Power Deliv. 2011, 26, 1764-1773. [CrossRef] 
100. Caldognetto, T.; Tenti, P. Microgrids operation based on master-slave cooperative control. IEEE J. Emerg. Sel. Top. Power Electron. 2014, 2, 1081-1088. [CrossRef]

101. Meng, X.; Liu, Z.; Liu, J.; Wu, T.; Wang, S.; Liu, B. A seamless transfer strategy based on special master and slave DGs. In Proceedings of the 2017 IEEE 3rd International Future Energy Electronics Conference and ECCE Asia (IFEEC 2017-ECCE Asia), Kaohsiung, Taiwan, 3-7 June 2017; Volume 1, pp. 1553-1558.

102. Cagnano, A.; De Tuglie, E.; Cervi, A.; Stecca, R.; Turri, R.; Vian, A. Re-Synchronization control strategy for master-slave controlled microgrids. In Proceedings of the 2019 1st International Conference on Energy Transition in the Mediterranean Area (SyNERGY MED), Cagliari, Italy, 28-30 May 2019; pp. 1-6.

103. Xu, Y. Robust Finite-Time Control for Autonomous Operation of an Inverter-Based Microgrid. IEEE Trans. Ind. Inform. 2017, 13, 2717-2725. [CrossRef]

104. Zuo, S.; Davoudi, A.; Song, Y.; Lewis, F.L. Distributed Finite-Time Voltage and Frequency Restoration in Islanded AC Microgrids. IEEE Trans. Ind. Electron. 2016, 63, 5988-5997. [CrossRef]

105. Chiang, H.-C.; Jen, K.-K.; You, G.-H. Improved droop control method with precise current sharing and voltage regulation. IET Power Electron. 2016, 9, 789-800. [CrossRef]

106. Ramos, R.; Biel, D.; Guinjoan, F.; Fossas, E. Sliding mode design of distributed central limit control strategy for parallel-connected inverters. In Proceedings of the VIII IEEE International Power Electronics Congress, 2002. Technical Proceedings. CIEP 2002, Guadalajara, Mexico, 24 October 2002; pp. 197-201.

107. Banda, J.; Siri, K. Improved central-limit control for parallel-operation of DC-DC power converters. In Proceedings of the PESC '95-Power Electronics Specialist Conference, Atlanta, GA, USA, 18-22 June 1995; pp. 1104-1110.

108. Weckx, S.; Gonzalez, C.; Driesen, J. Combined Central and Local Active and Reactive Power Control of PV Inverters. IEEE Trans. Sustain. Energy 2014, 5, 776-784. [CrossRef]

109. Furuhashi, T.; Okuma, S.; Uchikawa, Y. A study on the theory of instantaneous reactive power. IEEE Trans. Ind. Electron. 1990, 37, 86-90. [CrossRef]

110. Czarnecki, L. Closure on "Instantaneous Reactive Power p-q Theory and Power Properties of Three-Phase Systems". IEEE Trans. Power Deliv. 2008, 23, 1695-1696. [CrossRef]

111. Harirchi, F.; Simões, M.G. Enhanced Instantaneous Power Theory Decomposition for Power Quality Smart Converter Applications. IEEE Trans. Power Electron. 2018, 33, 9344-9359. [CrossRef]

112. Herrera, R.; Salmerón, P. Present point of view about the instantaneous reactive power theory. IET Power Electron. 2009, 2, 484-495. [CrossRef]

113. Montanari, A.A.; Gole, A.M. Enhanced Instantaneous Power Theory for Control of Grid Connected Voltage Sourced Converters under Unbalanced Conditions. IEEE Trans. Power Electron. 2016, 32, 6652-6660. [CrossRef]

114. Trivedi, T.A.; Jadeja, R.; Bhatt, P. A Review on Direct Power Control for Applications to Grid Connected PWM Converters. Eng. Technol. Appl. Sci. Res. 2015, 5, 841-849. [CrossRef]

115. Jain, B.; Jain, S.; Nema, R. Control strategies of grid interfaced wind energy conversion system: An overview. Renew. Sustain. Energy Rev. 2015, 47, 983-996. [CrossRef]

116. Dehkordi, N.M.; Sadati, N.; Hamzeh, M. Distributed Robust Finite-Time Secondary Voltage and Frequency Control of Islanded Microgrids. IEEE Trans. Power Syst. 2017, 32, 3648-3659. [CrossRef]

117. Guo, F.; Wen, C.; Mao, J.; Song, Y.D. Distributed Secondary Voltage and Frequency Restoration Control of Droop-Controlled Inverter-Based Microgrids. IEEE Trans. Ind. Electron. 2015, 62, 4355-4364. [CrossRef]

118. Shafiee, Q.; Vasquez, J.C.; Guerrero,J.M. Distributed secondary control for islanded MicroGrids—A networked control systems approach. In Proceedings of the IECON 2012-38th Annual Conference on IEEE Industrial Electronics Society, Montreal, QC, Canada, 25-28 October 2012; pp. 5637-5642. [CrossRef]

119. Wang, X.; Zhang, H.; Li, C. Distributed finite-time cooperative control of droop-controlled microgrids under switching topology. IET Renew. Power Gener. 2017, 11, 707-714. [CrossRef]

120. Zhou, J.; Kim, S.; Zhang, H.; Sun, Q.; Han, R. Consensus-Based Distributed Control for Accurate Reactive, Harmonic, and Imbalance Power Sharing in Microgrids. IEEE Trans. Smart Grid 2018, 9, 2453-2467. [CrossRef]

121. Shi, J.; Yue, N.; Weng, S. Distributed event-triggered mechanism for secondary voltage control with microgrids. Trans. Inst. Meas. Control 2018, 41, 1553-1561. [CrossRef]

122. Abdolmaleki, B.; Shafiee, Q.; Seifi, A.R.; Arefi, M.M.; Blaabjerg, F. A Zeno-Free Event-Triggered Secondary Control for AC Microgrids. IEEE Trans. Smart Grid 2020, 11, 1905-1916. [CrossRef] 
123. Fu, A.; Mazo, M. Traffic Models of Periodic Event-Triggered Control Systems. IEEE Trans. Autom. Control 2019, 64, 3453-3460. [CrossRef]

124. Heemels, W.P.M.H.; Donkers, M.C.F.; Teel, A.R. Periodic event-triggered control for linear systems. IEEE Trans. Autom. Control 2013, 58, 847-861. [CrossRef]

125. Qian, T.; Liu, Y.; Zhang, W.; Tang, W.; Shahidehpour, M. Event-Triggered Updating Method in Centralized and Distributed Secondary Controls for Islanded Microgrid Restoration. IEEE Trans. Smart Grid 2020, 11, 1387-1395. [CrossRef]

126. Yazdani, D.; Pahlevaninezhad, M.; Bakhshai, A. Three-phase grid synchronization techniques for grid connected converters in distributed generation systems. In Proceedings of the 2009 IEEE International Symposium on Industrial Electronics, Seoul, Korea, 5-8 July 2009; pp. 1105-1110. [CrossRef]

127. Cho, C.; Jeon, J.; Kim, J.; Kwon, S.; Park, K.; Kim, S. Active Synchronizing Control of a Microgrid. IEEE Trans. Power Electron. 2011, 26, 3707-3719. [CrossRef]

128. Zhong, Q.-C.; Ming, W.-L.; Zeng, Y. Self-Synchronized Universal Droop Controller. IEEE Access 2016, 4, 7145-7153. [CrossRef]

129. Zhong, Q.-C.; Nguyen, P.-L.; Ma, Z.; Sheng, W. Self-Synchronized Synchronverters: Inverters without a Dedicated Synchronization Unit. IEEE Trans. Power Electron. 2014, 29, 617-630. [CrossRef]

130. Ashabani, M.; Freijedo, F.D.; Golestan, S.; Guerrero, J.M. Inducverters: PLL-Less Converters with Auto-Synchronization and Emulated Inertia Capability. IEEE Trans. Smart Grid 2016, 7, 1660-1674. [CrossRef]

131. Tang, F.; Guerrero, J.M.; Vasquez, J.C.; Wu, D.; Meng, L. Distributed Active Synchronization Strategy for Microgrid Seamless Reconnection to the Grid under Unbalance and Harmonic Distortion. IEEE Trans. Smart Grid 2015, 6, 2757-2769. [CrossRef]

132. Ramos, C.J.; Martins, A.P.; Carvalho, A.S. Frequency and Phase-Angle Estimation Using Ordinary Least Squares. IEEE Trans. Ind. Electron. 2015, 62, 5677-5688. [CrossRef]

133. McGrath, B.P.; Holmes, D.G.; Galloway, J.J.H.G. Power Converter Line Synchronization Using a Discrete Fourier Transform (DFT) Based on a Variable Sample Rate. IEEE Trans. Power Electron. 2005, 20, 877-884. [CrossRef]

134. Golestan, S.; Guerrero, J.M.; Vasquez, J.C.; Abusorrah, A.M.; Al-Turki, Y. Modeling, Tuning, and Performance Comparison of Second-Order-Generalized-Integrator-Based FLLs. IEEE Trans. Power Electron. 2018, 33, 10229-10239. [CrossRef]

135. Liu, B.; Zhuo, F.; Zhu, Y.; Yi, H.; Wang, F. A Three-Phase PLL Algorithm Based on Signal Reforming under Distorted Grid Conditions. IEEE Trans. Power Electron. 2015, 30, 5272-5283. [CrossRef]

136. Yazdani, D.; Bakhshai, A.; Jain, P.K. Grid synchronization techniques for converter interfaced distributed generation systems. In Proceedings of the 2009 IEEE Energy Conversion Congress and Exposition, San Jose, CA, USA, 20-24 September 2009; pp. 2007-2014. [CrossRef]

137. Ali, Z.; Christofides, N.; Hadjidemetriou, L.; Kyriakides, E.; Guo, Q.; Blaabjerg, F. Three-phase phase-locked loop synchronization algorithms for grid-connected renewable energy systems: A review. Renew. Sustain. Energy Rev. 2018, 90, 434-452. [CrossRef]

138. Rasheduzzaman, M.; Kimball, J.W. Modeling and Tuning of an Improved Delayed-Signal-Cancellation PLL for Microgrid Application. IEEE Trans. Energy Convers. 2018, 34, 712-721. [CrossRef]

139. Ramezani, M.; Golestan, S.; Li, S.; Guerrero, J.M. A Simple Approach to Enhance the Performance of Complex-Coefficient Filter-Based PLL in Grid-Connected Applications. IEEE Trans. Ind. Electron. 2017, 65, 5081-5085. [CrossRef]

140. Taul, M.G.; Wang, X.; Davari, P.; Blaabjerg, F. An Overview of Assessment Methods for Synchronization Stability of Grid-Connected Converters under Severe Symmetrical Grid Faults. IEEE Trans. Power Electron. 2019, 34, 9655-9670. [CrossRef]

141. Reza, S.; Sadeque, F.; Hossain, M.; Ghias, A.; Agelidis, V.G.; Agelidis, V.G. Three-Phase PLL for Grid-Connected Power Converters under Both Amplitude and Phase Unbalanced Conditions. IEEE Trans. Ind. Electron. 2019, 66, 8881-8891. [CrossRef]

142. Escobar, G.; Martinez-Montejano, M.F.; Valdez, A.A.; Martinez, P.R.; Hernandez-Gomez, M. Fixed-ReferenceFrame Phase-Locked Loop for Grid Synchronization under Unbalanced Operation. IEEE Trans. Ind. Electron. 2010, 58, 1943-1951. [CrossRef]

143. Wu, F.; Zhang, L.; Duan, J. A New Two-Phase Stationary-Frame-Based Enhanced PLL for Three-Phase Grid Synchronization. IEEE Trans. Circuits Syst. II Express Briefs 2015, 62, 251-255. [CrossRef] 
144. Guerrero-Rodríguez, N.F.; Rey-Boué, A.B.; Bueno, E.J.; Ortiz, O.; Reyes-Archundia, E. Synchronization algorithms for grid-connected renewable systems: Overview, tests and comparative analysis. Renew. Sustain. Energy Rev. 2017, 75, 629-643. [CrossRef]

145. Tong, L.; Zou, X.; Feng, S.; Chen, Y.; Kang, Y.; Huang, Q.; Huang, Y. An SRF-PLL-Based Sensorless Vector Control Using the Predictive Deadbeat Algorithm for the Direct-Driven Permanent Magnet Synchronous Generator. IEEE Trans. Power Electron. 2013, 29, 2837-2849. [CrossRef]

146. Chung, S.-K. A phase tracking system for three phase utility interface inverters. IEEE Trans. Power Electron. 2000, 15, 431-438. [CrossRef]

147. Golestan, S.; Monfared, M.; Freijedo, F.D. Design-Oriented Study of Advanced Synchronous Reference Frame Phase-Locked Loops. IEEE Trans. Power Electron. 2012, 28, 765-778. [CrossRef]

148. Rocabert, J.; Azevedo, G.M.S.; Luna, A.; Guerrero, J.M.; Candela, J.I.; Rodríguez, P. Intelligent Connection Agent for Three-Phase Grid-Connected Microgrids. IEEE Trans. Power Electron. 2011, 26, 2993-3005. [CrossRef]

149. Rodríguez, P.; Pou, J.; Bergas, J.; Candela, J.I.; Burgos, R.P.; Boroyevich, D. Decoupled double synchronous reference frame PLL for power converters control. IEEE Trans. Power Electron. 2007, 22, 584-592. [CrossRef]

150. Da Silva, C.H.; Pereira, R.R.; Da Silva, L.E.B.; Lambert-Torres, G.; Bose, B.K.; Ahn, S.U. A Digital PLL Scheme for Three-Phase System Using Modified Synchronous Reference Frame. IEEE Trans. Ind. Electron. 2010, 57, 3814-3821. [CrossRef]

151. González-Espín, F.J.; Figueres, E.; Garcera, G. An Adaptive Synchronous-Reference-Frame Phase-Locked Loop for Power Quality Improvement in a Polluted Utility Grid. IEEE Trans. Ind. Electron. 2012, 59, 2718-2731. [CrossRef]

152. Yada, H.K.; Kumar, A.S.; Prakash, K. Improved dual-SOGI control for three-phase unified power quality conditioner under distorted grid and load conditions. In Proceedings of the TENCON 2017-2017 IEEE Region 10 Conference, Penang, Malaysia, 5-8 November 2017; pp. 2536-2541.

153. Golestan, S.; Mousazadeh, S.Y.; Guerrero, J.M.; Vasquez, J.C. A Critical Examination of Frequency-Fixed Second-Order Generalized Integrator-Based Phase-Locked Loops. IEEE Trans. Power Electron. 2017, 32, 6666-6672. [CrossRef]

154. Xiao, F.; Dong, L.; Li, L.; Liao, X. A Frequency-Fixed SOGI-Based PLL for Single-Phase Grid-Connected Converters. IEEE Trans. Power Electron. 2017, 32, 1713-1719. [CrossRef]

155. Guan, Q.; Zhang, Y.; Kang, Y.; Guerrero, J.M. Single-Phase Phase-Locked Loop Based on Derivative Elements. IEEE Trans. Power Electron. 2016, 32, 4411-4420. [CrossRef]

156. Mojiri, M.; Bakhshai, A. Stability analysis of periodic orbit of an adaptive notch filter for frequency estimation of a periodic signal. Automatica 2007, 43, 450-455. [CrossRef]

157. Yazdani, D.; Mojiri, M.; Bakhshai, A.; Joós, G. A Fast and Accurate Synchronization Technique for Extraction of Symmetrical Components. IEEE Trans. Power Electron. 2009, 24, 674-684. [CrossRef]

158. Martínez-Montejano, M.; Escobar, G.; Torres-Olguin, R. Fixed reference frame phase-locked loop (FRF-PLL) for unbalanced line voltage conditions. In Proceedings of the 2008 IEEE Power Electronics Specialists Conference, Rhodes, Greece, 15-19 June 2008; pp. 4723-4728.

159. Karimi-Ghartemani, M.; Mojiri, M.; Safaee, A.; Walseth, J.A.; Khajehoddin, S.A.; Jain, P.; Bakhshai, A. A New Phase-Locked Loop System for Three-Phase Applications. IEEE Trans. Power Electron. 2013, 28, 1208-1218. [CrossRef]

160. Golestan, S.; Guerrero, J.M.; Musavi, F.; Vasquez, J.C. Single-Phase Frequency-Locked Loops: A Comprehensive Review. IEEE Trans. Power Electron. 2019, 34, 11791-11812. [CrossRef]

161. Rodríguez, P.; Luna, A.; Muñoz-Aguilar, R.S.; Etxeberria-Otadui, I.; Teodorescu, R.; Blaabjerg, F. A Stationary Reference Frame Grid Synchronization System for Three-Phase Grid-Connected Power Converters under Adverse Grid Conditions. IEEE Trans. Power Electron. 2012, 27, 99-112. [CrossRef]

162. Yi, H.; Wang, X.; Blaabjerg, F.; Zhuo, F. Impedance Analysis of SOGI-FLL-Based Grid Synchronization. IEEE Trans. Power Electron. 2017, 32, 7409-7413. [CrossRef]

163. He, X.; Geng, H.; Yang, G. A Generalized Design Framework of Notch Filter Based Frequency-Locked Loop for Three-Phase Grid Voltage. IEEE Trans. Ind. Electron. 2018, 65, 7072-7084. [CrossRef]

164. Vazquez-Oviedo, E.I.; Vázquez, N.; Femat, R. Synchronization Technique of Grid-Connected Power Converters Based on a Limit Cycle Oscillator. IEEE Trans. Ind. Electron. 2017, 65, 709-717. [CrossRef] 
165. Rodriguez, P.; Luna, A.; Candela, I.; Mujal, R.; Teodorescu, R.; Blaabjerg, F. Multiresonant Frequency-Locked Loop for Grid Synchronization of Power Converters Under Distorted Grid Conditions. IEEE Trans. Ind. Electron. 2011, 58, 127-138. [CrossRef]

166. Overney, F.; Mortara, A. Synchronization of sampling-based measuring systesm. IEEE Trans. Instrum. Meas. 2014, 63, 89-95. [CrossRef]

167. Reza, S.; Ciobotaru, M.; Agelidis, V.G. Single-Phase Grid Voltage Frequency Estimation Using Teager Energy Operator-Based Technique. IEEE J. Emerg. Sel. Top. Power Electron. 2015, 3, 1218-1227. [CrossRef]

168. Babu, B.C.; Sridharan, K.; Rosolowski, E.; Leonowicz, Z.M. Analysis of SDFT based phase detection system for grid synchronization of distributed generation systems. Eng. Sci. Technol. Int. J. 2014, 17, 270-278. [CrossRef]

169. Retegui, R.G.; Gonzalez, S.A.; Funes, M.A.; Maestri, S. Implementation of a novel synchronization method using Sliding Goertzel DFT. In Proceedings of the 2007 IEEE International Symposium on Intelligent Signal Processing, Alcala de Henares, Spain, 3-5 October 2007. [CrossRef]

170. Baradarani, F.; Zadeh, M.R.D.; Zamani, M.A. A Phase-Angle Estimation Method for Synchronization of Grid-Connected Power-Electronic Converters. IEEE Trans. Power Deliv. 2014, 30, 827-835. [CrossRef]

171. Romano, P.; Paolone, M. Enhanced interpolated-DFT for synchrophasor estimation in FPGAs: Theory, implementation, and validation of a PMU prototype. IEEE Trans. Instrum. Meas. 2014, 63, 2824-2836. [CrossRef]

172. Belega, D.; Macii, D.; Petri, D. Fast Synchrophasor Estimation by Means of Frequency-Domain and Time-Domain Algorithms. IEEE Trans. Instrum. Meas. 2013, 63, 388-401. [CrossRef]

173. Song, H.-S.; Nam, K. Instantaneous phase-angle estimation algorithm under unbalanced voltage-sag conditions. IEE Proc. Gener. Transm. Distrib. 2000, 147, 409-415. [CrossRef]

174. Chen, C.-I. A Phasor Estimator for Synchronization Between Power Grid and Distributed Generation System. IEEE Trans. Ind. Electron. 2013, 60, 3248-3255. [CrossRef]

175. Kusljevic, M.D.; Tomic, J.J.; Jovanovic, L.D. Frequency Estimation of Three-Phase Power System Using Weighted-Least-Square Algorithm and Adaptive FIR Filtering. IEEE Trans. Instrum. Meas. 2009, 59, 322-329. [CrossRef]

176. Zhong, Q.-C.; Weiss, G. Synchronverters: Inverters That Mimic Synchronous Generators. IEEE Trans. Ind. Electron. 2011, 58, 1259-1267. [CrossRef]

177. Bevrani, H.; Ise, T.; Miura, Y. Virtual synchronous generators: A survey and new perspectives. Int. J. Electr. Power Energy Syst. 2014, 54, 244-254. [CrossRef]

178. Belila, A.; Amirat, Y.; Benbouzid, M.; Berkouk, E.M.; Yao, G. Virtual synchronous generators for voltage synchronization of a hybrid PV-diesel power system. Int. J. Electr. Power Energy Syst. 2020, 117, 105677. [CrossRef]

179. Wang, X.; Chen, L.; Sun, D.; Zhang, L.; Nian, H. A Modified Self-Synchronized Synchronverter in Unbalanced Power Grids with Balanced Currents and Restrained Power Ripples. Energies 2019, 12, 923. [CrossRef]

180. Blaabjerg, F.; Teodorescu, R.; Liserre, M.; Timbus, A.V. Overview of Control and Grid Synchronization for Distributed Power Generation Systems. IEEE Trans. Ind. Electron. 2006, 53, 1398-1409. [CrossRef]

Publisher's Note: MDPI stays neutral with regard to jurisdictional claims in published maps and institutional affiliations.

(C) 2020 by the authors. Licensee MDPI, Basel, Switzerland. This article is an open access article distributed under the terms and conditions of the Creative Commons Attribution (CC BY) license (http://creativecommons.org/licenses/by/4.0/). 